This is the final peer-reviewed accepted manuscript of:

Maria Alessandra Ancona, Francesco Baldi, Michele Bianchi, Lisa Branchini, Francesco Melino, Antonio Peretto, Jessica Rosati

Efficiency Improvement On a Cruise Ship: Load Allocation Optimization,

Energy Conversion and Management, Volume 164, 2018, p. $42-58$

The final published version is available online at:

https://doi.org/10.1016/j.enconman.2018.02.080

(C) 2018. This manuscript version is made available under the Creative Commons AttributionNonCommercial-NoDerivs (CC BY-NC-ND) 4.0 International License

(http://creativecommons.org/licenses/by-nc-nd/4.0/) 


\title{
Efficiency Improvement On a Cruise Ship: Load Allocation Optimization
}

\author{
M. A. Ancona ${ }^{\mathrm{a}}$, F. Baldi ${ }^{\mathrm{b}}$, M. Bianchic, L. Branchini ${ }^{\mathrm{a}}$, F. Melino ${ }^{\mathrm{c}}$, A. Peretto ${ }^{\mathrm{c}}$, J. Rosati ${ }^{\mathrm{c}, *}$ \\ ${ }^{\mathrm{a}}$ CIRI-EA - Alma Mater Studiorum, via Angherà, 22, 47900 Rimini \\ ${ }^{\mathrm{b}}$ Department of Shipping and Marine Technology - Chalmers University of Technology, 41276 Gothenburg, Sweden \\ ${ }^{\mathrm{c}}$ Department of Industrial Engineering - DIN - Alma Mater Studiorum, viale del Risorgimento 2, 40136, Bologna \\ *corresponding author: e-mail: jessica.rosati3@unibo.it, phone: +39-051-2093320
}

\begin{abstract}
Last years have been characterized by a worldwide increasing attention towards the reduction of fuel consumption and carbon dioxide emissions. Several industrial fields, as well as the civil and residential sector, have introduced innovative approaches for the design and the operation of energy systems. These actions are aimed to reach higher values of energy conversion efficiency, also including an increase in the use of renewable resources. In this context, especially in the sector of cruise ships, further efforts are required to improve the energy efficiency of the employed energy systems. The aim of this paper is to propose an optimization framework based on genetic algorithms in order to maximize the energy efficiency and minimize both the fuel consumption and the thermal energy dissipation, by optimizing the load allocation of the ship energy systems. To this purpose, different strategies for the energy systems on board of an existing cruise ship are proposed and analyzed. In particular, two main engines configurations have been defined: standard (current logic of operation maintained) and hybrid configuration. For each proposed strategy - being the ship a particular and interesting application of isolated energy grid (i.e. a grid without connections with electric and fuel national grids) - an in-house-developed software has been adapted and applied to optimize the load allocation of the various energy systems. Furthermore, an economic and environmental analysis has been carried out, in order to point out the benefits - or the eventual limits - related to the proposed solutions. The considered approach is based on the concept of introducing economically and structurally suitable modifications to the current cruise energy systems configuration, in order to reach the goal of increasing the energy efficiency. The carried out analysis shows that the hybrid strategies allow to reach the best results in terms of energy (fuel consumption and heat dissipation reduction), economic and environmental points of view.
\end{abstract}

Keywords: Energy Efficiency Increase; Energy Systems Load Optimization; Genetic Algorithm; Optimization Method; Shipping Energy Efficiency; Thermal Storage.

\section{NOMENCLATURE}

Symbols

$C \quad \operatorname{cost}[€]$

$C F_{i} \quad$ cash flow $[€]$

COP coefficient of performance [-]

$E \quad$ energy [kWh or MWh]

EER energy efficiency ratio [-]

$h \quad$ hours [h]

$I_{0} \quad$ initial investment cost $[€]$

$L \quad$ load [-]

$n \quad$ number of units [-]

$N \quad$ number of years [year]

$P \quad$ power $[\mathrm{kW}]$

$r \quad$ discount rate [-]

$T \quad$ temperature $\left[{ }^{\circ} \mathrm{C}\right.$ or $\left.\mathrm{K}\right]$

Greek Symbols

$\eta \quad$ efficiency [-]

$\mu \quad$ cost of maintenance $[€ / \mathrm{kW}]$

$\xi \quad$ cost of electricity [€/kW or $€ / \mathrm{kWh}]$

Subscripts and Superscripts

DES design

disp dispersed 


\begin{tabular}{|c|c|c|}
\hline 55 & $E$ & electricity \\
\hline 56 & $E L$ & electrical \\
\hline 57 & $e q$ & equivalent \\
\hline 58 & $F$ & fictitious \\
\hline 59 & $F R$ & cooling \\
\hline 60 & fuel & fuel \\
\hline 61 & $m$ & mechanical \\
\hline 62 & $M$ & maintenance \\
\hline 63 & $S T$ & storage \\
\hline 64 & $T H$ & thermal \\
\hline 65 & tot & total \\
\hline 66 & $\lambda$ & fuel \\
\hline 67 & & \\
\hline 68 & Acronyms & \\
\hline 69 & $A B$ & auxiliary boilers \\
\hline 70 & $A C$ & absorption boilers \\
\hline 71 & $B C$ & base case \\
\hline 72 & $C C$ & compression chiller \\
\hline 73 & $\mathrm{CHP}$ & combined heat and power \\
\hline 74 & $\mathrm{CO}$ & carbon oxide \\
\hline 75 & $\mathrm{CO}_{2}$ & carbon dioxide \\
\hline 76 & $E G O$ & energy grid optimizer \\
\hline 77 & $E S$ & electrical storage \\
\hline 78 & $F F$ & fitness function \\
\hline 79 & $F T$ & fuel tank \\
\hline 80 & $H P$ & heat pumps \\
\hline 81 & $H Y$ & hybrid \\
\hline 82 & $H Y-S$ & hybrid with storage \\
\hline 83 & $H Y-S-A C$ & hybrid with storage and absorption chiller \\
\hline 84 & IMO & international maritime organization \\
\hline 85 & NMVOC & non-methane volatile organic compound \\
\hline 86 & $N O_{X}$ & nitrogen oxides \\
\hline 87 & $N P V$ & net present value \\
\hline 88 & $O L$ & optimized load \\
\hline 89 & $O L-S$ & optimized load with storage \\
\hline 90 & ORC & organic Rankine cycle \\
\hline 91 & $P M$ & prime mover \\
\hline 92 & $P M \mathrm{~s}$ & particulate matters \\
\hline 93 & $R G_{e}$ & renewable electrical generator \\
\hline 94 & $R G_{t}$ & renewable thermal generator \\
\hline 95 & $S O_{X}$ & sulphur oxides \\
\hline 96 & $T S$ & thermal storage \\
\hline
\end{tabular}

\section{1. INTRODUCTION}

\subsection{Background}

The development of new strategies to improve energy efficiency is one of the major challenges that world has to face today. Indeed, energy efficiency increase is playing a key role relating to the sustainable future planning [1-3].

One of the main reasons why research increasingly focuses on this topic lies into the global warming problem, primarily generated by greenhouse gas emissions, especially $\mathrm{CO}_{2}$, as output of fossil fuels combustion [4-5]. This issue has been increasingly considered as fundamental in different fields, i.e. industrial, civil and domestic sectors. However, only in the last years the legislation in the transport sector and particularly in the maritime transport, where the contribution to greenhouse gases emission cannot be neglected, has been rearranged.

Shipping industry seems to play a minor role in regard to global anthropogenic $\mathrm{CO}_{2}$ emissions, since it represents only the $3 \%$ of the whole emissions, as of 2012 [1]. In fact, as it can be noted from Figure 1 [6], that shows the $\mathrm{CO}_{2}$ emissions from fuel combustion by different sector, the shipping sector contribution is equal to $3.3 \%$ (including the international shipping and the domestic shipping and fishing).

However, relating to the shipping industry, it has to be considered that more than $40 \%$ of the total shipping costs is attributed to fuel consumption [7]. Moreover, despite of its current low contribution, many predictions indicate for the next future an 
increase in shipping volumes (which means, obviously, emissions increase) [8]. As a consequence, energy efficiency management and control are fundamental aspects to account for fuel costs savings and $\mathrm{CO}_{2}$ emissions reduction.

In this scenario both national and international energy policies increasingly focus on new solutions for energy systems optimization and efficiency maximization. Recently, the International Maritime Organization introduced relevant regulations and is continuously improving the standards of ship energy saving and emissions reduction [9-10]. With regard to this goal, even the European Union is starting actions to achieve a reduction on transport's carbon emissions of $60 \%$ by 2050 . In particular, focusing on the European scenario, the goal is a reduction of $\mathrm{CO}_{2}$ emissions ranging from $40 \%$ up to $50 \%$ [11].

\subsection{Energy efficiency in shipping}

In order to achieve the previous goals, the shipping sector has developed new approaches to reduce the fuel consumption. Some actions [12-17] relate to the ship operation, such as: (i) adapting routes in order to avoid conditions of bad weather, so reducing the negative impact of high waves and strong wind on ship fuel consumption, (ii) maximizing the transported cargo while reducing the length of ballast legs and (iii) improving trim and draft settings, together with the optimization of the schedules and the practices for hull and propeller polishing, leading to reduced ship resistance for a given speed, etc.

Other actions [18-24] are related to new technical solutions with the purpose of improving the performance of on board specific systems, such as the engines, the propeller, the hull, etc. In the last years, some other strategies for the emissions control have been developed. Some alternatives, for example, act on the energy efficiency improvement by decreasing the time of port stay. Another strategy, instead, consists in navigation speed regulation: studies show that the fuel consumption can be reduced by determining the optimal engine speed, with an achievable reduction of about the $19 \%$ with respect to the typical fuel consumption per distance unit [18-24].

Some researchers focus on waste heat recovery. A valid technique consists in the application of energy storage devices for engines heat recovering [27-28]. In particular, thermal storage can be seen as a promising solution for the energy efficiency increase in marine transport field. The implementation in the shipping field of this simple solution (and/or other more complex thermal storage solutions), therefore, enables the achievement of benefits, in terms of primary energy saving (through an optimal use of resources), costs reduction (fuel consumption reduction) and environmental impact (through a reduction of greenhouse gases). Moreover, the adoption of a fuel cell in addition to an energy storage device has been studied in [29]. Another approach is the adoption of an absorption refrigerator [30] to recover the thermal dissipation from the engines; finally, the heat recovery can be realized considering the integration of marine diesel engines with an organic Rankine cycle (ORC) system [31-33].

Different studies have been conducted as it regards the vessels' power management. To this purpose, some researchers [35] have proposed a dynamic load management method which takes into account the equality and inequality constraints of a certain system. Another study [36], instead, pointed out a three stages method, based on the operational cost minimization, to find out an optimal power management solution and to limit the greenhouse gas emissions without changing the technical and operational constraints. In [37-40] further methods have been proposed to model the power plant of an isolated system and to find out an optimal load allocation of the vessel's components.

\subsection{Aim}

In this context, this paper proposes the use of an optimization framework based on genetic algorithms in order to optimize the operations of ship energy systems, maximizing the energy efficiency and minimizing the fuel consumption. Compared to previous efforts in the literature, the proposed approach has two main advantages: compared to a Mixed Integer Linear Approach (MILP) (e.g. [41-43]), it retains the influences of nonlinear phenomena, and particularly of energy systems efficiencies. Compared to traditional Mixed Integer Nonlinear approaches (MINLP) (e.g. [37]), it is more robust against the risk of falling into local optima and less computational intensive. The combination of these two advantages allows to treat problems of high complexity, as the optimization of ship energy systems, particularly when energy storage is included, creating a strong coupling among the optimization parameters.

The use of genetic algorithms for the optimal load allocation of ship energy systems, with particular reference to electric and thermal energy storage, has not been proposed before in the existing scientific literature (as for the best Authors knowledge) and it constitutes the main element of novelty of this work.

The paper is structured as follows: in Section 2 the current configuration and the energy needs of the considered ship is described; in Section 3 the calculation model used for the simulations is presented; in Section 4 the hypothesis and assumptions are listed and, finally, in Section 5 the results of the simulations are presented and discussed.

\section{CASE STUDY}

The case study analyzed in the paper is a cruise ship operating in the Baltic Sea between Stockholm (in Swedish mainland) and Mariehamn (in the Åland islands). The vessel is 177 meters long and about 28 meters wide with a design speed equal to 21 knots. Because of its capacity - up to 1.800 passengers - the vessel can be considered a medium size cruise ship. The ship is equipped with restaurants, clubs and bars, as well as saunas and pools. 
The ship makes the same daily route during the whole year (365 days/year) as shown in Figure 2 . On the basis of its route and according to the available information, the ship operational early profile can be divided among ( $i$ ) sea going, (ii) port stay or sea stay and (iii) maneuvering, as presented in Figure 3. From the figure, it can be noted that the port and sea stay operation represents around one third of the total operational profile.

\subsection{Energy Demand}

The energy demand of the considered ship consists of (i) mechanical energy (for propulsion), (ii) electrical energy (for lighting, cold appliance, hot appliance, auxiliary systems, etc.), (iii) thermal energy (mainly for space heating and hot water production) and (iv) cooling energy (only during the summer period).

The vessel typical operational profile is always the same: the departure from Stockholm is scheduled around 6:00 PM; the ship reaches the open sea where it stops for few hours during the night before reaching Mariehamn port early in the morning. Then the ship leaves Mariehamn around 9:00 AM to go back to Stockholm where the arrivals are scheduled around 4:00 PM.

Thus, the mechanical energy demand is almost the same every day, while - since the travel's conditions (i.e. weather condition) change - the thermal and cooling energy requests are different depending on the considered season.

The characterization of the energy needs of the ship could be done according to the operational modes taking into account the following considerations:

- when the cruise ship is at the harbor (port stay) or laying in open sea (sea stay) the demand consists of electrical and thermal energy (and cooling energy during the summer period) in order to guarantee the services of the ship for the boarding and alighting of passengers (port stay) and for their comfort on board (sea stay);

- $\quad$ during the sailing (sea going) the demand reaches its maximum values in terms of mechanical demand;

- when the ship enters or leaves the port (maneuvering) the mechanical demand is intermediate between the one of sea going and the one corresponding to port stay or sea stay.

- the electrical and thermal (for space heating and/or hot water production) demands are not influenced by the operational profiles of the cruise.

The aforementioned considerations, together with an experimental data collection made on board [37], allow to estimate the hourly load profile curves of mechanical, thermal, electrical and cooling power for typical days during winter, summer and spring/fall, as presented in Figure 4. More details about the elaboration of these curves can be found in [37].

Relating to the duration of each season, according to the average monthly temperatures in Sweden [44], the following assumptions can be made:

winter: 182 days (since January the $1^{\text {st }}$ to April the $15^{\text {th }}$ and since October the $16^{\text {th }}$ to December the $31^{\text {st }}$ );

summer: 62 days (since July the $1^{\text {st }}$ to August the $31^{\text {st }}$ )

spring/fall: 121 days (since April the $16^{\text {th }}$ to June the $30^{\text {st }}$ and since September the $1^{\text {st }}$ to October the $15^{\text {th }}$ ).

From Figure 4 it can be observed that the mechanical power demand for propulsion is the same for each season as the electrical demand. In particular, for the mechanical power, it is possible to note that it is equal to zero during the port stay and when the ship is drifting offshore. This behavior is consistent with the fact that the movement of the propellers, generated by the mechanical power, is stopped when it is not necessary to the movement of the ship.

For what regards the thermal power demand, the maximum request occurs, as expected, during the winter period while it is minimum during the summer, when only the hot water needs are accounted. The maximum request of thermal power is equal to slightly more than $7 \mathrm{MW}$ : the shape of the load curve shows two peaks respectively during the first hours of the day and between 7:00 PM and 9:00 PM.

Furthermore, it can be observed that electrical and thermal power are never equal to zero. This evidence can be explained considering that the continued operation of safety systems (smoke detectors, gas detectors, fixed fire-fighting equipment, alarms, emergency lights, etc.) and minimum comfort on-board (lighting, entertainment, space heating, hot water, etc.) are ensured. Moreover, being a vessel used for passengers' transport, it must always be guaranteed electrical power (in addition to lighting, also for equipment for the preservation and preparation of food, refrigerators, etc.) and thermal power (for example for the heating of the cabins) also during the port stay phase. On the other hand, during the summer a cooling power is required and, as can be noted from the figure, its trend is almost constant with an average value around $1^{\circ} 000 \mathrm{~kW}$.

\subsection{Energy Systems}

The ship is currently equipped with eight marine diesel engines (PM) according to the scheme presented in Figure 5. Four main engines (4× Wärtsilä 6L46 - from PM\#01 to PM\#04 in Figure 5) for mechanical power production and four auxiliaries' engines (4× Wärtsilä 6L32 - from PM\#05 to PM\#08 in Figure 5) for electrical power production are installed. The PM design performance are listed in Table 1.

All the PM on board are medium speed [47-48], being characterized by 500 RPM and 750 RPM respectively for main and auxiliary engines. 
As it can be observed from Figure 5, the main engines are divided in two groups (gearboxes), each one providing energy to only one propeller. It follows that the mechanical demand is divided into two equal parts which means that at least two main engines are always operated if mechanical power is requested.

The ship thermal demand can be satisfied by recovering waste heat from all the eight engines and by the use of two auxiliary boilers. The two auxiliary boilers are characterized by a maximum thermal power output equal to $4.500 \mathrm{~kW}$ (each) and by a thermal efficiency in design condition equal to $80 \%$. Furthermore, a compression chiller system is included for cooling power production. This chiller shows a maximum cooling power output equal to $2^{\circ} 000 \mathrm{~kW}$ with an EER assumed equal to 3.5 , in design condition.

\section{CALCULATION MODEL}

In order to minimize the ship fuel consumption, an in-house-developed software has been applied [49]. In details, this software - developed by University of Bologna and named EGO (Energy Grids $\underline{\text { Optimizer}) ~-~ i s ~ a b l e ~ t o ~ d e f i n e ~ t h e ~ l o a d ~ d i s t r i b u t i o n ~ o f ~ a ~}$ number of energy systems operating into a grid, with the aim of minimizing the total cost of energy production.

In particular, the realized software can simulate an energy grid consisting in $(i)$ an arbitrary number of prime movers (PM) even in CHP (Combined Heat and Power) application, (ii) generators from renewable source (solar thermal panels - RGt wind turbines and photovoltaic panels - RGe), (iii) energy storage devices (ES) for both electrical and thermal energy, (iv) thermal generators (auxiliary boilers - AB - and heat pumps - HP) and ( $v$ ) cooling machines (compressor - CC - and absorption chillers - AC). The aforementioned generators are used to cover the electrical, thermal and cooling energy load requested by a utility (or a group of utilities); the simulated grid can also be connected (if present) with the electric grid and with the gas distribution network. The adopted software and its regulation strategies and mathematical models have been validated in [49]. It should be highlighted that the developed software has been adapted for this study: this scenario, indeed, can be seen as a particular application of energy grid operating without connection to the electric distribution network.

The calculation core of the realized in-house-developed software consists of a genetic algorithm based on the minimization of an objective function which expresses the total cost of energy production.

The input section requires:

- $\quad$ electrical, thermal and cooling power required by the utilities; further is also possible to define the gas demand (for direct use) for the utilities;

- $\quad$ the number, typology, and main characteristics of:

○ prime movers (electrical and thermal design power output, efficiency, off-design behaviour, etc.);

- renewable source generators (peak power, performance, etc.);

○ heating and cooling systems (size, performance, off-design behaviour, etc.):

○ electric and thermal energy storage devices (maximum storable energy);

- $\quad$ the tariff scenario (purchased and sold electric energy value, cost of the fuel, etc.);

- a series of parameters characteristic of the genetic algorithm (as better explained in the following of this paragraph).

The optimal load of each considered energy systems in order to minimize the total cost of the energy supplied to the users and the costs of energy production represents the main output of the software.

\subsection{Mathematical Model}

With the aim to reach the goals of energy efficiency increase and fuel consumption reduction, the configurations analyzed in this study are based on the specific mathematical model presented in this section. The developed genetic algorithm, indeed, is based on the minimization of the following fitness function $(F F)$ :

$F F=C_{\lambda}+C_{M}+C_{E}+C_{F}$ where:

- $\quad C_{\lambda}$ is the total cost of fuel and it can be calculated as:

$C_{\lambda}=\left[\sum_{i=1}^{n_{P M}} f_{\lambda, i}^{P M}\left(L_{P M, i}\right)+\sum_{i=1}^{n_{A B}} f_{\lambda, i}^{A B}\left(L_{A B, i}\right)\right] \cdot \lambda_{\text {fuel }}$

where the functions $f_{\lambda, i}^{P M}, f_{\lambda, i}^{A B}$ express the power introduced with fuel in the $i^{\text {th }}$ prime mover or auxiliary boiler as function of the systems loads $\left(L_{P M, i}\right.$ and $\left.L_{A B, i}\right)$. Furthermore, $\lambda_{\text {fuel }}$ is the cost of the fuel (expressed as $€ / \mathrm{kW}$ ) introduced in prime movers and/or auxiliary boilers.

- $\quad C_{M}$ is the total maintenance cost of the energy systems. This parameter is estimated as function of the produced power electrical (EL), thermal (TH) or cooling (FR) - of each system and is calculated by using maintenance cost specific values $\left(\mu_{i}\right.$ expressed in $\left.€ / \mathrm{kW}\right)$ :

$C_{M}=\sum_{i=1}^{n_{P M}+n_{R G e}} P_{E L, i} \cdot \mu_{E L, i}+\sum_{i=1}^{n_{R G t}+n_{A B}+n_{B B}+n_{H P}} P_{T H, i} \cdot \mu_{T H, i}+\sum_{i=1}^{n_{C C}+n_{A C}} P_{F R, i} \cdot \mu_{F R, i}$ where $P_{i}$ is function of the load of each system $P_{i}=f\left(L_{i}\right)$.

- $\quad C_{E}$ is the total cost of the electricity purchased from the national grid and can be estimated as: 
being $\xi_{E L, P}$ the specific cost of purchased electricity $(€ / \mathrm{kW})$ and $P_{E L, P}$ the total electric power from the distribution network to the users. It can be seen that $P_{E L, P}$, if greater than zero, can be expressed as:

$$
P_{E L, P}=\sum_{i=1}^{n_{U}} P_{E L, i}^{U}+\sum_{i=1}^{n_{C C}} \frac{P_{F R, i}^{C C}}{f_{E E R, i}^{C C}\left(L_{C C, i}\right)}+\sum_{i=1}^{n_{H P}} \frac{P_{T H, i}^{H P}}{f_{C O P, i}^{H P}\left(L_{H P, i}\right)}-\sum_{i=1}^{n_{R G e}} f_{E L, i}^{R G e}\left(L_{R G e, i}\right)-\sum_{i=1}^{n_{P M}} f_{E L, i}^{P M}\left(L_{P M, i}\right)-\sum_{i=1}^{n_{E S}} P_{E L, i}^{E S}
$$

The previous expression represents the sum of the electrical power required from the users (U), from the compressor chillers (CC) and from the heat pumps (HP) minus the production of the eventual renewable source generators (RG), of the prime movers and the power recovered from electrical storage devices (ES). Moreover, $f_{C O P, i}^{H P}$ and $f_{C O P, i}^{H P}$ represent two functions which estimate respectively the energy efficiency ratio (EER) of the cooling machines and the coefficient of performance $(\mathrm{COP})$ of the heat pumps as function of the systems loads $\left(L_{C C, i}\right.$ and $\left.L_{H P, i}\right)$. Finally, in Eq. E6.5, the function $f_{E L, i}^{P M}$ calculates the produced power of the $i^{\text {th }}$ prime mover for a given load $\left(L_{P M, i}\right)$.

- $\quad C_{F}$ are the so-called fictitious costs. In details, $C_{F}$ allows to force the regulation strategy of the whole energy grid according to the rules of the thermal priority or of the electrical priority. In case of regulation with thermal priority, in order to minimize the environmental impact of the prime movers, a fictitious cost has been introduced to take into account the dissipation of thermal power discharged by the prime movers and not used for the utilities. With this regulation strategy, if more electricity is generated compared to utilities' needs and storage availability, surplus can be sold to the network (if connected to the calculated energy grid). Conversely, the regulation strategy with electrical priority discourages the sale of electricity to the grid by considering, opposite to the previous case, this option as a cost. This strategy can be adopted in case of a smart grid not connected to the network (such as the case under investigation) or if the national grid is not suitable to accommodate energy.

In case of thermal priority, it results:

$C_{F}=\sum_{i=1}^{n_{P M}} \frac{Q_{\text {disp }, i}}{\eta_{A B, a v}} \cdot \lambda_{\text {fuel }} \cdot p_{T}-P_{E L, S} \cdot \xi_{E L, S}$

In the previous relationship, it can be observed that the thermal energy dispersed to the stack $\left(Q_{\text {disp, } i}\right)$ is accounted as a cost by considering it as a multiple $\left(p_{T}\right)$ of the corresponding fuel cost used in a conventional boiler to produce the same amount of dispersed heat. In this case, the sale of electricity to the network is accounted as a reduction of the costs of electricity production considering a specific value $\xi_{E L, S}(€ / \mathrm{kW})$.

Otherwise, if electrical priority is adopted, the fictitious costs become:

$C_{F}=P_{E L, S} \cdot \xi_{E L, S} \cdot p_{E}$

where, the sale of electricity to the grid $\left(P_{E L, S}\right)$ is discouraged considering, as already said, this option as a cost. As well as for thermal priority, a multiplication factor $\left(p_{E}\right)$ has been assumed, while the dispersion of heat from the prime movers to the environment is not considered as a cost.

Beyond that, the software allows a combined priority which is defined as a mix of the previous strategies. On the basis of the previous equations, it can be written:

$C_{F}=\sum_{i=1}^{n_{P M}} \frac{Q_{\text {disp }, i}}{\eta_{A B, a v}} \cdot \lambda_{\text {fuel }} \cdot p_{T}+P_{E L, S} \cdot \xi_{E L, S} \cdot p_{E}$

Eq. E6.8 clearly shows that with this regulation strategy, both the dissipation of thermal energy to the stack and the sale of electrical energy to the network are simultaneously discouraged. This is the approach adopted for the case studies.

\subsection{Genetic Algorithm}

In order to minimize the fitness function $(F F)$ the genetic algorithm creates and/or evolves a population of candidate solutions, in which the loads $\left(L_{i}\right)$ of the systems installed within the grid represent the chromosomes of each individual. The values of $L_{i}$ allow the estimation of the $F F$ on the basis of the previous equations. The evolution of the population starts from a first generation which is randomly generated. This approach, as known, is usually adopted for the genetic algorithm.

It can be noted that the size $\left(p_{S}\right)$ of the population (i.e. the number of individuals) is defined as function of the total number the systems $\left(n_{t o t}\right)$ included in the smart grid. It results:

$p_{S}=P_{F M} \cdot\left(L_{U P}-L_{L O}\right) \cdot n_{\text {tot }}$

where $L_{U P}$ and $L_{L O}$ are the upper and lower limits of the variation range of the terms $L_{i}$, while $P_{F M}$ is a multiplicative parameter (an integer number greater than 1). $P_{F M}$ represents a tuning parameter which influences the convergence velocity of the algorithm. Low values of $P_{F M}$ mean few individuals for each generation, thus the convergence of the algorithm can require a large number of iterations. On the other hand, high number of individuals reduces the number of required iterations but increases the time required for each iteration.

Once the first generation is created, for each of its individuals the $F F$ is estimated and then a $F F$ rank is created. Solutions with lower values of energy production cost are represented by individuals with lower values of $F F$ and then are recognized as high rank solutions; on the contrary, solutions with higher values of $F F$ become low rank solutions. A defined percentage of lower rank solutions (usually between $50 \%$ and $75 \%$ of the total population) is automatically eliminated from the generation. The remaining individuals are instead involved into the creation of the next generation. The generation of new individuals follows the crossover method (also known as recombination method) without mutation. This means that two new 
individuals are generated by two parent individuals. To guarantee that individuals with higher rank have higher probability (under the statistical point of view) of generating a new individual, the selection of the parent individuals is realized with a roulette method. The highest rank solution $F F R \# 1(i)$ of each generation (with the exception of the first one) is compared with the corresponding of the previous generation, $F F R \# 1(i-1)$. When the difference between these two quantities is lower than a given tolerance value $T O L$, the procedure ends:

$|F F R \# 1(i)-F F R \# 1(i-1)|<T O L$

\section{HYPOTHESIS AND ASSUMPTIONS}

In this section, the main hypothesis and assumptions of the study will be presented and discussed. In particular, different onboard energy systems configurations are proposed (section 4.1) and the applied model for the off-design operation of the main engines, the auxiliary engines, the auxiliary boilers, etc. (section 4.2) are discussed.

\subsection{Energy Systems Configurations and Operational Strategies}

In order to determinate the optimal configuration and operational strategy for the energy systems of the considered ship, six different configurations have been proposed: the first three strategies are characterized by a standard configuration, that is the current engines regulation, typical for this type of ships.

The remaining three strategies, instead, are characterized by a hybrid configuration of the engines, which is broadly used today on the military ships.

In details:

$\underline{\text { BC }} \quad \underline{B}$ ase Case - the first strategy considers the energy system scheme presented in Figure 5, corresponding to the current layout of the vessel. In this case, both the mechanical and electrical powers are satisfied by equally sharing the production among the corresponding engines; this management strategy - not currently adopted in this ship - is based on the equal incremental cost criterion which is used in power generation sector [49];

OL Optimized Load - in this second strategy the energy system scheme is still the one shown in Figure $\mathbf{5}$. However, differently from the previous case, the load of each engine is determined by the developed software in order to minimize the fuel consumption and the wasted thermal energy;

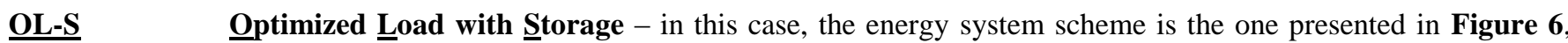
which comes from the one in Figure 5 with the addition of a thermal storage device; also in this case the load of each engine is determined by the developed software;

$\underline{\text { HY }}$

HYbrid - the fourth strategy is characterized by a different configuration of the engines compared to the previous ones. In this case, in fact, has been considered an hybrid system - as is shown in Figure 7 - in which all the engines produce electrical power and the propulsion is realized by means of two electrical engines instead of the two gearboxes;

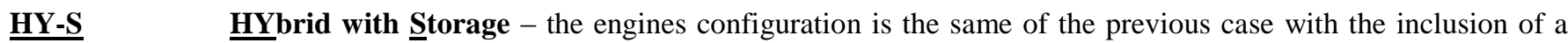
thermal storage tank (see Figure 8);

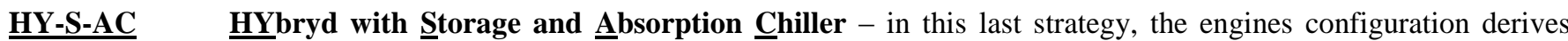
from the previous one (HY and HY-S) with a further introduction of an absorption chiller unit, as presented in Figure 9.

Each of these configurations has been implemented in the EGO software considering the energy demand curves presented in Figure 4. The calculation has been developed considering - as already explained - three reference days (winter, summer and spring/fall typical days). The main results of the simulations will be presented for a whole year (365 days) of ship operation. Furthermore, relating to the configurations OL-S, HY-S and HY-S-AC, the thermal storage volume was part of the optimization: the storage volume has been estimated in order to minimize both the auxiliary boilers fuel consumption and the thermal energy from the internal combustion engines wasted through the chimney.

\subsection{Energy Systems Off-design Operation and Other Assumptions}

The off-design behavior of the main and of the auxiliary engines was considered according to the curves respectively presented in Figure 10 and in Figure 11. It can be observed that the main engines show the maximum value of mechanical efficiency $(44.7 \%$ ) for a load equal to the $80 \%$, while - again with reference to $80 \%$ load - the thermal efficiency reaches its minimum 
value $(45.3 \%)$. Differently, the auxiliary engines are characterized by a maximum value of electrical efficiency (42.8 \%) and a minimum value of thermal efficiency $(47.2 \%)$ with reference to full load operation. Further details about the calculation methodology used to derive the curves in Figure 10 and in Figure 11 can be found in the Authors' previous paper [37].

As regards the auxiliary boilers, the trend of the thermal efficiency as function of the load is presented in Figure 12. This curve, which shows the maximum value $(80 \%)$ for a boiler load equal to $30 \%$, was estimated according to the evidence that generally - for marine applications - boilers are characterized by high performance, even at very low loads [50]. Furthermore, the EER trend as function of compression chiller load is presented in Figure 13. The plotted trend is typical of this kind of machines and was estimated according to the literature on this matter [51]. Finally, for what regards the EER of the absorption chiller (see HY-S-AC strategy in Figure 9), a constant value equal to 0.67 was considered [51].

A cylindrical insulated tank has been considered as thermal storage device, assuming a global heat exchange coefficient equal to $0.5 \mathrm{~W} / \mathrm{m}^{2} \mathrm{~K}$ [52]. As previously mentioned, the choice of the optimal volume of the tank is a result of the developed analysis. Furthermore, for the auxiliary components, such as gearbox, frequency converter, etc. (for simplicity not included in the schemes in Figure 5 and from Figure 6 to Figure 9, with the exception of electrical engines and of gearboxes between main engines and propellers), a constant value of the efficiency was taken into account. The assumed values are presented in Table 2 [53-55].

Finally, a constant value of efficiency (equal to 0.97) was assumed for the thermal and cooling energies distribution systems from the production devices to the final users.

\section{RESULTS}

In this section the results of the yearly simulations for the operational strategies and configurations described in section 4.1 will be presented.

In details, section 5.1 presents the energetic analysis which mainly takes into account the vessel's consumption with a comparison between the different developed strategies; section 5.2 presents a simplified economic analysis with a Net Present Value (NPV) evaluation and introduces a briefly environmental analysis on main pollutant emissions.

\subsection{Energetic Analysis}

The yearly fuel consumption of the auxiliary boilers and the annual wasted thermal energy trends are presented respectively in Figure 14 and in Figure 15, expressed as function of the thermal storage volume. In these figures, the green line represents the standard configuration, analyzed through the three first strategies (BC, OL and OL-S) while the blue line represents the hybrid configuration (HY, HY-S and HY-S-AC).

From Figure 14 it can be observed that, compared to the base case strategy (BC), the OL configuration involves a greater auxiliary boilers fuel consumption, as it will be better explained in the following.

By the application of a thermal energy storage to the OL configuration (OL-S strategy) it can be observed that the auxiliary boilers fuel consumption (green line) decreases with the increase in the storage volume. It has to be also observed that for a storage volume equal to $11.5 \mathrm{~m}^{3}$, the consumption increase in OL strategy with respect to the BC strategy can be reduced to zero (see Figure 14, red dotted line). With a further increase in the storage volume, it can be noted that the auxiliary boilers fuel consumption reaches the complete boilers shut-down for a storage volume equal to $61 \mathrm{~m}^{3}$ (for this reason, it can be considered as the optimal volume for the standard configuration).

For what regards the hybrid configurations (blue line), from Figure 14 it can be observed that the fuel consumption of the boilers is greater than the OL strategy (and the Base Case). This occurs without considering the thermal storage. In fact, with the introduction of a storage tank, the boilers fuel consumption decreases and, even in this case, for a value of $22.7 \mathrm{~m}^{3}(\mathrm{see}$ red dotted line), it equals the fuel consumption of the BC strategy. Moreover, it can be observed that also for the hybrid strategy, the storage application involves an auxiliary boiler shut-down. In this case this occurs for a tank volume of $69 \mathrm{~m}^{3}$.

Relating to the thermal dissipations, instead, the reverse situation occurs, (see Figure 15). In fact, by applying the OL strategy (optimized standard configuration) the heat losses decrease. Moreover, considering the thermal storage, this decrease is greater until a storage volume of $61 \mathrm{~m}^{3}$ beyond which this reduction will be imperceptible.

The same consideration can be done for the hybrid configurations. This strategy, indeed, involve a greater benefit in terms of heat dissipations compared to both the base case and the standard configuration. The storage volume identified as optimal is 69 $\mathrm{m}^{3}$ (HY-S and HY-S-AC strategies).

On the basis of all these considerations, the aforementioned volumes can be fixed as the minimum and the optimal ones. In particular, for the standard configuration they are respectively $11.5 \mathrm{~m}^{3}$ and $61 \mathrm{~m}^{3}$, while for the hybrid configuration they correspond to $22.7 \mathrm{~m}^{3}$ and $69 \mathrm{~m}^{3}$. On the other hand, the optimal thermal storage volumes (that avoid the boilers fuel consumption) evidently correspond to the maximum volumes which allow to recover all the heat discharged from the engines. In other words, the previous assumption means that the maximum values of thermal storage volumes do not necessarily reduce the dispersed thermal energy to zero (see Figure 15). In addition, it should be obviously verified the possibility to install these devices on board, according to the available space.

Furthermore, from Figure 14 it has to be observed that the hybrid configuration is always characterized by a higher auxiliary boilers fuel consumption and a higher optimal storage volume compared to the standard configuration and the base case. 
However, this is true if only the auxiliary boilers fuel consumption is considered, but - for a better evaluation of the strategies effectiveness - the total fuel consumption (shown in Figure 16) should be considered. In Figure 16 contributions of auxiliary boilers and prime movers to the yearly fuel consumption are presented separately.

At the same time, the annual dispersed thermal energy has been reported in Figure 17.

It must be pointed out that the results presented in these figures are in reference to the optimal volumes of thermal energy storage devices aforementioned, where implemented (OL-S, HY-S and HY-S-AC strategies).

From Figure 16 it can be noted that the maximum fuel consumption is achieved in the base case, with a total amount slightly higher than $104^{\circ} 000 \mathrm{MWh}$; in this case the total thermal dispersed energy is equal to more than $26^{\circ} 000 \mathrm{MWh}$ (see Figure 17). These values decrease with the adoption of an optimal management strategy, as results from the developed calculation code application (OL). The reductions in fuel consumption and dispersed thermal energy, indeed, are respectively close to $8 \%$ and less than $29 \%$. On this regard, it must be noted that the fuel consumption reduction is due to the fact that, moving from BC to OL strategy, the consumption increase for auxiliary boilers (as aforementioned for Figure 14) for an amount around $47 \%$, is counterbalanced by the consumption decrease for engines (equals about $10 \%$ ). This evidence can be explained considering the optimal operation of the engines (which results in a different load allocation with respect to the BC) that increases the conversion efficiency and consequently - being equal for each configuration the produced energy (mechanical, electrical, thermal and cooling) - reduces the available thermal energy from the engines. The adoption of thermal energy storage (OL-S) further reduces the fuel consumption by completely shutting down the auxiliary boilers (as said for Figure 14), while the operation of both main and auxiliary engines remains the same of case OL-S.

As expected, the optimal volume of thermal storage allows to reduce the dissipated thermal energy up to a value greater than $14^{\circ} 000 \mathrm{MWh}$, which corresponds to about the $57 \%$ reduction with respect to the BC strategy.

For what concern the hybrid configurations, instead, the HY strategy allows a reduction of fuel with respect to the base case. Anyway, the total amount of both fuel consumption and dissipated thermal energy is lightly higher than for OL-S configuration. The adoption of a hybrid configuration, indeed, allows a greater flexibility relating to the engines load allocation: it follows that the engines fuel consumption from OL-S to HY reduces from more than $90^{\circ} 000 \mathrm{MWh}$ to $84^{\circ} 400$ MWh, even if an increase in dispersed thermal energy occurs (about the $4 \%$ greater than OL-S).

It should be considered that this slight increase in thermal losses is observed without the use of storage, which means that the engines load allocation of HY appears to be more efficient than OL-S. The absence of thermal storage entails the adoption of auxiliary boilers: in this case about $7 \cdot 100 \mathrm{MWh}$ of fuel consumption are accounted, representing the highest value among all the analyzed configurations. This evidence confirms the fact that the optimization of load allocation involves a reduction in the engines fuel consumption and a contemporary increase in the auxiliary boilers employment. Thus, considering HY-S, the adoption of the thermal storage allows eliminating all fuel consumption of auxiliary boilers and reducing the dispersed thermal energy to about 10.000 MWh. As already observed for OL and OL-S, also moving from HY to HY-S the thermal storage allows the complete boilers shut-down but does not affect the engines load allocation. Finally, the introduction of absorption chiller, enables the further reduction of the dissipated thermal energy (which decreases of about $72 \%$ and $27 \%$ compared to BC and HY-S respectively). As regards the fuel consumption, HY-S-AC shows a slightly reduction with respect to HY-S, mainly due to the lower electrical demand of the compression chiller.

In Figure 18, the yearly operational equivalent hours (defined as the ratio between the annual produced energy and the design power) are presented for each system (absorption chiller, compression chiller, auxiliary boilers, main engines - from PM\#01 to PM\#04 - and auxiliary engines - from PM\#05 to PM\#08) and for each strategy. It should be highlighted that the reduction of the operational equivalent hours, for a given system, means a reduction of its maintenance costs. Furthermore, from Figure 18 it can be noted that - moving from BC to OL and OL-S - no variations occur in the operational equivalent hours of the main engines, the auxiliary engines and the compression chiller. The only difference, in these three cases, stands in the equivalent hours of the auxiliary boilers. Likewise, HY and HY-S are characterized by the same values of equivalent hours both in case of main and auxiliary engines. Comparing HY and HY-S with the previous three strategies (BC, OL and OL-S), it is observed an increase in the operational equivalent hours of the main engines and a decrease for auxiliary ones. This is due to the application of the software, which favors the engines with a greater conversion efficiency (see Table 1). Furthermore, HY strategy shows an increase in auxiliary boilers' operating hours with respect to the base case (BC), while in HY-S - as already explained - this value is equal to zero. Equivalent hours of compression chiller do not show any changes, as expected, referring to strategies from BC to HY-S. Finally, for HY-S-AC, due to the use of absorption chiller, a reduction of electrical load occurs. This fact clearly results in a reduction of the operational equivalent hours for compression chiller, with a consequent decrease in the use of auxiliary engines. Furthermore, a slightly increase in the operational equivalent hours of main engines is observed.

\subsection{Economic and Environmental Analysis}

In Figure 19 the yearly operating costs, accounting for fuel consumption and maintenance costs, are presented.

The calculation has been made considering the assumption [56-57] listed in Table 3.

From Figure 19 it can be noted that the main contribution to the total variable costs is attributed to the fuel costs. The total maintenance cost value varies between $550^{\circ} 000 €$ and 580.000 $€$, representing a small percentage (around $7 \%$ of the total variable costs. Based on this consideration, it can be said that the maintenance costs can be considered quite constant with the considered strategy. Furthermore, with reference to the figure, it can be noted that OL-S involves a performance improvement in terms of yearly variable costs (around $13 \%$ reduction) with a moderate investment for its application. Compared to the 
current layout of the ship, the engines configuration remains the same, while the main change is represented by the installation of a tank for the thermal energy storage.

Relating to HY-S and HY-S-AC, instead, a further reduction on the annual variable costs can be reached (around $18 \%$ and $20 \%$ for HY-S and HY-S-AC respectively, with reference to the fuel cost reduction). In this case, however, it has to be considered not only the storage tank installation, but also a reconfiguration of the engines from the traditional to the hybrid operation. Furthermore, HY-S-AC strategy needs an absorption chiller unit installation.

With reference to Figure 19, it can be determined the annual money saving for each developed strategy compared to the base case, considering the differential cash flow.

A simplified economic analysis has been carried out based on the Net Present Value (NPV), defined as:

$$
N P V=-I_{0}+\sum_{i=1}^{N} \frac{C F_{i}}{(1+r)^{i}}
$$

where $I_{0}$ represents the total initial investment cost, $r$ is the discount rate, assumed equal to $7 \%, N$ is the time horizon, and $C F_{i}$ is the net cash inflow during the period $t$.

Setting $N P V=0$, the maximum investment cost sustainable to pay back the expenditure in $N$ years can be determined:

$$
I_{0}=\sum_{i=1}^{N} \frac{C F_{i}}{(1+r)^{i}}
$$

The maximum investment cost, calculated for each developed strategy and evaluated considering periods of 2 years (red columns) and 5 years (blue columns), is shown in Figure 20.

From the figure, it can be noted that for the OL strategy the investment costs are relatively low, ranging from around $1^{\circ} 000^{\circ} 000 €$ to around $3^{\circ} 000^{\circ} 000 €$. Increasing the complexity of the adopted strategy, the sustainable maximum investment increases up to $7^{\circ} 000^{\circ} 000 €(\mathrm{HY}-\mathrm{S}-\mathrm{AC})$.

In the following Table 4, the emissions factors of the main pollutant - such as Carbon Oxide $(\mathrm{CO}), \mathrm{Carbon}$ Dioxide $\left(\mathrm{CO}_{2}\right)$, Nitrogen Oxides $\left(\mathrm{NO}_{\mathrm{X}}\right)$, Sulphur Oxides $\left(\mathrm{SO}_{\mathrm{X}}\right)$, Particulate Matters (PMs) and Non-Methane Volatile Organic Compounds (NMVOC) - have been reported according to the Third IMO GHG study [8]. These values - representing the average emissions related to the specific naval sector - refers to marine diesel oil (MDO) considered as input fuel used for all the energy systems: main engines, auxiliary engines and boilers. It has to be noted that these values depend on the engines speed; in this case, as aforementioned, the engines can be classified as medium-speed engines (see Section 2.2).

It has to be specified that the following analysis is a simplified evaluation carried out considering the average values of the emissions factors and neither pollutant control system or strategies nor the corresponding legislation have been taken into account.

Starting from these emissions factors values, the corresponding emissions quantities - for each developed strategy - have been calculated and reported in Figure 21.

From Figure $21 \boldsymbol{a}$ it can be noted that, for what regards the $\mathrm{CO}_{2}$ emissions, they vary from a maximum of about 30.000 ton $_{\mathrm{CO} 2}$ /year to a minimum of about $24^{\circ} 000$ ton $_{\mathrm{CO} 2} /$ year, corresponding to the Base Case and the $\mathrm{HY}-\mathrm{S}-\mathrm{AC}$ strategies, respectively. Because of these high values, the dioxide carbon can be considered the main pollutant emission.

Another significant emission is represented by the Nitrogen Oxides $\left(\mathrm{NO}_{\mathrm{X}}\right)$, shown in Figure 21b. These pollutant emissions,

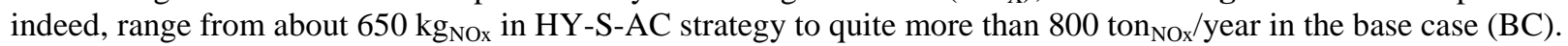

Other minor but significant pollutant emissions, such as the PMs, CO, NMVOC and $\mathrm{SO}_{\mathrm{X}}$, have been presented in Figure 21c. In this figure it can be observed that moving from BC strategy to the HY-S-AC, the Particulate Matter varies from around 8 to 10 tons/year; the $\mathrm{SO}_{\mathrm{X}}$, instead, ranges from about 20 to 25 tons/year; the CO from 21 to 26 tons/year and, finally, the NMVOC varies from 23 to 29 tons/year. On the whole, it can be observed that the standard configurations (from BC to OL-S) can reach a maximum decrease of the pollutant emissions equal to $14 \%$; with the hybrid configurations, these emissions further decrease up to $20 \%$ (from BC to HY-S-AC).

\section{CONCLUDING REMARKS}

One of the major challenges that world has to face today consists of new strategies development in order to improve energy efficiency and to reduce pollutant emissions. In particular, the contribution of the maritime transport to greenhouse gases emission cannot be neglected and more than $40 \%$ of the total shipping costs is attributed to fuel consumption.

In this paper five different strategies to improve the energy efficiency of a medium size cruise ship have been developed and compared to actual cruise operation. In more detail, two general main configurations have been considered: the standard configuration, which is the current engine system of the vessel without any substantial change except for the storage tank application - i.e. base case (BC), optimized load (OL) and optimized load with storage (OL-S) strategies - and the hybrid configuration, which considers a different engines equipment and, in some case, the storage tank introduction - i.e. hybrid (HY), hybrid with storage (HY-S) and hybrid with storage and absorption chiller (HY-S.AC) strategies. 
For each of the developed strategies, energy, economic and environmental analyses have been conducted. For what concerns the energetic evaluation, a parametric analysis on the storage volume has been carried out to minimize the annual amount of both the auxiliary boilers fuel consumption and heat losses. From this analysis, the optimal and the maximum storage volume have been identified. Furthermore, the equivalent hours of operation for each of the considered strategies have been evaluated. The results show that the developed strategies allow to reach both a yearly fuel consumption and dispersed thermal energy decrease compared to current engines operation. These advantages become significant if a thermal storage tank is considered. As regards the standard scenario, the optimal volume has to be considered between $11.5 \mathrm{~m}^{3}$ and $61 \mathrm{~m}^{3}$; for the hybrid scenario, instead, the minimum and maximum values are $22.7 \mathrm{~m}^{3}$ and $69 \mathrm{~m}^{3}$, respectively. On the whole, the total annual operational equivalent hours, to which are associated the maintenance costs, decreases for those strategies that include the thermal energy storage.

For what regards the economic analysis, a simplified Net Present Value evaluation, based on the differential cash flow has been made, in order to investigate the maximum investment cost to pay back the expenditure of each strategies in 2 and 5 years. The annual variable costs of each strategy and in particular the maintenance and fuel costs have been considered, highlighting the strong influence of the fuel cost on the total outlay.

Finally, a simplified environmental analysis has been carried out considering the main pollutant emissions, such as $\mathrm{CO} \mathrm{CO}_{2}$, $\mathrm{NO}_{\mathrm{X}}, \mathrm{SO}_{\mathrm{X}}, \mathrm{PMs}$ and NMVOC. From the results appear that the maximum reduction of the pollutant emission can be reached applying the HY-S-AC strategy (about $20 \%$ ). In terms of $\mathrm{CO}_{2}$, a yearly reduction of about the $20 \%$ can be achieved (HY-SAC). 


\section{REFERENCES}

[1] Johnson, H., \& Styhre, L. (2015). Increased energy efficiency in short sea shipping through decreased time in port. Transportation Research Part A: Policy and Practice, 71, 167-178.

[2] Rehmatulla, N., \& Smith, T. (2015). Barriers to energy efficiency in shipping: A triangulated approach to investigate the principal agent problem. Energy Policy,84, 44-57.

[3] Wang, K., Yan, X., Yuan, Y., \& Li, F. (2016). Real-time optimization of ship energy efficiency based on the prediction technology of working condition. Transportation Research Part D: Transport and Environment, 46, 81-93.

[4] Rahim, M. M., Islam, M. T., \& Kuruppu, S. (2016). Regulating global shipping corporations' accountability for reducing greenhouse gas emissions in the seas.Marine Policy, 69, 159-170.

[5] Liljestrand, K. (2016). Improvement actions for reducing transport's impact on climate: A shipper's perspective. Transportation Research Part D: Transport and Environment, 48, 393-407.

[6] Quadrelli, R., \& Peterson, S. (2007). The energy-climate challenge: recent trends in CO 2 emissions from fuel combustion. Energy policy, 35(11), 5938-5952.

[7] Jang, S. H., \& Choi, J. H. (2016). Comparison of fuel consumption and emission characteristics of various marine heavy fuel additives. Applied Energy, 179, 36-44.

[8] Smith, T.W.P., Jalkanen, J.P., Anderson, B.A., Corbett, J.J., Faber, J., Hanayama, S., et al. Third IMO GHG Study. London, UK; 2014.

[9] Anderson, K., Bows, A. Executing a Scharnow turn: reconciling shipping emissions with international commitments on climate change. Carbon Manage 2012;3:615-28.

[10] Lindstad, H. E., \& Eskeland, G. S. (2016). Environmental regulations in shipping: Policies leaning towards globalization of scrubbers deserve scrutiny.Transportation Research Part D: Transport and Environment, 47, 67-76.

[11] EC. Roadmap to a single european transport area - towards a competitive and resource efficient transport system. Brussels, Belgium; 2011.

[12] Norstad, I., Fagerholt, K., Laporte, G. Tramp ship routing and scheduling with speed optimization. Transp Res Part C Emerg Technol 2011;19:853-65.

[13] Nishida, T., Katori, M., Uzawa, K., Ohuchi, K., Waseda, T. Optimization of integrated weather routing systems for sailing cargo ships. In: Proceeding 21st int offshore polar eng conf, Maui, USA, vol. 8; 2011. p. 283-9.

[14] Shao, W., Zhou, P., Thong, S.K. Development of a novel forward dynamic programming method for weather routing. J Mar Sci Technol 2006;11:239-51.

[15] Kim, H., Choi, S.S., Hong, C., Yoo, S., Seo, J., Hwangbo, S., et al. Development and application of trim optimization and parametric techniques using an evaluation system (SoLuTion) based on the RANS for improvement of EEOI. ASME; 2013. p. 784-91. vol. 2 CFD VIV.

[16] Moustafa, M.M., Yehia, W., Hussein, A.W. Energy efficient operation of bulk carriers by trim optimization. In: Altosole M, Francescutto A, editors. Proc $18^{\text {th }}$ int conf ships shipp res, Lecco, Italy; 2015.

[17] Petersen, J.P., Winther, O., Jacobsen, D.J. A machine-learning approach to predict main energy consumption under realistic operational conditions. Sh Technol Res 2012;59:64-72.

[18] Kindt, S. State-of-the-art MAN B \& W two-stroke super-long-stroke engines. Proc Congr Int Counc Combust Engines 2013.

[19] Imperato, M. Some experimental experience gained with a medium-speed diesel research engine. Proc Congr Int Counc Combust Engines 2010.

[20] Risse, S., Gmbh, K.B., Buchmann, K. New turbochargers for modern large engines with low emissions and high performance. Proc Congr Int Counc Combust Engines 2013.

[21] Aesoy, V., Magne Einang, P., Stenersen, D., Hennie, E., Valberg, I. LNG-fuelled engines and fuel systems for mediumspeed engines in maritime applications; 2011. http://dx.doi.org/10.4271/2011-01-1998.

[22] Xie, G. Optimal preliminary propeller design based on multi-objective optimization approach. Procedia Eng 2011;16:278-83.

[23] Motley, M.R., Nelson, M., Young, Y.L. Integrated probabilistic design of marine propulsors to minimize lifetime fuel consumption. Ocean Eng 2012;45:1-8.

[24] Hochkirch, K., Heimann, J., Bertram, V. Hull optimization for operational profile - the next game level. V Int Conf Comput Methods Mar Eng 2013.

[25] Johnson, H., Johansson, M., \& Andersson, K. (2014). Barriers to improving energy efficiency in short sea shipping: an action research case study. Journal of Cleaner Production, 66, 317-327.

[26] Johnson, H., \& Andersson, K. (2011). The energy efficiency gap in shipping-barriers to improvement. In International Association of Maritime Economists (IAME) Conference.

[27] Baldi, F., Gabrielii, C., Melino, F., Bianchi, M. A Preliminary Study on the Application of Thermal Storage to Merchant Ship

[28] Lashway, C. R., Elsayed, A. T., \& Mohammed, O. A. (2016). Hybrid energy storage management in ship power systems with multiple pulsed loads.Electric Power Systems Research, 141, 50-62.

[29] Bassam, A. M., Phillips, A. B., Turnock, S. R., \& Wilson, P. A. (2016). An improved energy management strategy for a hybrid fuel cell/battery passenger vessel. International Journal of Hydrogen Energy, 41(47), 22453-22464.

[30] Salmi, W., Vanttola, J., Elg, M., Kuosa, M., \& Lahdelma, R. (2017). Using waste heat of ship as energy source for an absorption refrigeration system. Applied Thermal Engineering. 
[31] Mondejar, M. E., Ahlgren, F., Thern, M., \& Genrup, M. (2017). Quasi-steady state simulation of an organic Rankine cycle for waste heat recovery in a passenger vessel. Applied Energy, 185, 1324-1335.

[32] Michos, C. N., Lion, S., Vlaskos, I., \& Taccani, R. (2017). Analysis of the backpressure effect of an Organic Rankine Cycle (ORC) evaporator on the exhaust line of a turbocharged heavy duty diesel power generator for marine applications. Energy Conversion and Management, 132, 347-360.

[33] Zhao, M., Wei, M., Song, P., Liu, Z., \& Tian, G. (2016). Performance evaluation of a diesel engine integrated with ORC system. Applied Thermal Engineering.

[34] Freeman, J., Hellgardt, K., \& Markides, C. N. (2017). Working fluid selection and electrical performance optimisation of a domestic solar-ORC combined heat and power system for year-round operation in the UK. Applied Energy, 186, 291303.

[35] Feng, X., Zourntos, T., Butler-Purry, K. L., \& Mashayekh, S. (2010, July). Dynamic load management for NG IPS ships. In Power and Energy Society General Meeting, 2010 IEEE (pp. 1-8). IEEE.

[36] Kanellos, F. D. (2014). Optimal power management with GHG emissions limitation in all-electric ship power systems comprising energy storage systems. IEEE Transactions on Power Systems, 29(1), 330-339.

[37] Baldi, F., Ahlgren, F., Melino, F., Gabrielii, C., \& Andersson, K. (2016). Optimal load allocation of complex ship power plants. Energy Conversion and Management, 124, 344-356.

[38] Radan, D., Johansen, T. A., Sorensen, A. J., \& Adnanes, A. K. (2005). Optimization of load dependent start tables in marine power management systems with blackout prevention. WSEAS Transactions on circuits and systems, 4(12), 18611866.

[39] Chen, C., Duan, S., Cai, T., Liu, B., \& Hu, G. (2011). Optimal allocation and economic analysis of energy storage system in microgrids. IEEE Transactions on Power Electronics, 26(10), 2762-2773.

[40] Türkoğulları, Y. B., Taskın, Z. C., Aras, N., \& Altınel, İ. K. (2016). Optimal berth allocation, time-variant quay crane assignment and scheduling with crane setups in container terminals. European Journal of Operational Research, 254(3), 985-1001.

[41] Garfinkel, R. S., \& Nemhauser, G. L. (1972). Integer programming (Vol. 4, pp. 214-216). New York: Wiley.

[42] Dai, R., \& Mesbahi, M. (2013). Optimal power generation and load management for off-grid hybrid power systems with renewable sources via mixed-integer programming. Energy Conversion and Management, 73, 234-244.

[43] Skjong, E., Johansen, T. A., Molinas, M., \& Sørensen, A. J. (2017). Approaches to Economic Energy Management in Diesel-Electric Marine Vessels. IEEE Transactions on Transportation Electrification, 3(1), 22-35.

[44] Climate Change Knowledge Portal - http://sdwebx.worldbank.org/climateportal/

[45] Wärtsilä 46 - Project guide for marine application

[46] Wärtsilä Engines - Wärtsilä 32

[47] Ntziachristos, L., Saukko, E., Lehtoranta, K., Rönkkö, T., Timonen, H., Simonen, P., ... \& Keskinen, J. (2016). Particle emissions characterization from a medium-speed marine diesel engine with two fuels at different sampling conditions. Fuel, 186, 456-465.

[48] Andersson, K., Brynolf, S., Lindgren, J. F., \& Wilewska-Bien, M. (Eds.). (2016). Shipping and the Environment: Improving Environmental Performance in Marine Transportation. Springer

[49] Ancona, M. A., Bianchi, M., Branchini, L., De Pascale, A., Melino, F., Orlandini, V., Peretto, A., "Generation Side Management in Smart Grid”, Proceedings of ASME-ATI-UIT 2015 Conference on Thermal Energy Systems: Production, Storage, Utilization and the Environment, 17 - 20 May, 2015, Napoli, Italy - ISBN 978-88-98273-17-1

[50] Cohen, L., Fritz, W.A. Efficiency determination of marine boilers: input-output versus heat-loss method. J Eng Power 1962:39-43.

[51] Macchi, E., Campanari, S., Silva, P. (2005). La microcogenerazione a gas naturale (p. 304). Polipress ISBN: 8873980163

[52] Ancona, M. A., Bianchi, M., Diolaiti, E., Giannuzzi, A., Marano, B., Melino, F., Peretto, A. (2016). A novel solar concentrator system for combined heat and power application in residential sector. Applied Energy. In Press, Corrected Proof, Available online 25 March 2016, doi:10.1016/j.apenergy.2016.03.026

[53] Shi, W., Stapersma, D., Grimmelius, H.T. Analysis of energy conversion in ship propulsion system in off-design operation conditions. WIT Trans Econogy Environ 2009;121:461-72.

[54] Dedes, E., Hudson, D.A., Turnock, S.R. Assessing the potential of hybrid energy technology to reduce exhaust emissions from global shipping. Energy Policy 2012;40:204-18.

[55] Ådanes, A.K. Maritime electrical installations and diesel electric propulsion. ABB AS Marine 2003.

[56] Andreoni, V., Miola, A., \& Perujo, A. (2008). Cost effectiveness analysis of the emission abatement in the shipping sector emissions. European Commission Joint Research Centre Institute for Environment and Sustainability, Luxembourg.

[57] Gunnarsson, G., Skúlason, J. B., Sigurbjarnarson, Á., Enge, S., (2016). Regenerative electric/hybrid drive train for ships RENSEA II, nordic innovation publication 2016:02 (http://www.nordicinnovation.org/Global/_Publications/Reports/2016/Rensea\%20rapport_final.pdf) 
Table 1 - Internal combustion engines design performance [44-45]

\begin{tabular}{|c|c|c|c|}
\hline Model & Wärtsilä 6L46 & Model & Wärtsilä 6L32 \\
\hline Mechanical Power [kW] & 5850 & Electrical Power $[\mathrm{kW}]$ & 2760 \\
\hline Thermal Power [kW] & 6081 & Thermal Power [kW] & 3049 \\
\hline Mechanical Efficiency [-] & 0.44 & Electrical Efficiency [-] & 0.43 \\
\hline Thermal Efficiency [-] & 0.46 & Thermal Efficiency [-] & 0.47 \\
\hline
\end{tabular}

Table 2 - Auxiliary components efficiencies [53-55]

\begin{tabular}{ll}
\hline Component & $\boldsymbol{\eta}_{\text {des }}$ \\
\hline Gearbox & 0.98 \\
Generator & 0.97 \\
Electrical Engine & 0.96 \\
Frequency converter & 0.98 \\
Shaft & 0.98 \\
\hline
\end{tabular}

Table 3 - Specific variable costs [56-57]

\begin{tabular}{lc}
\hline Costs & $\boldsymbol{€} / \mathbf{k W h}$ \\
\hline Fuel & 0.0843 \\
\hline Main Engine maintenance & 0.0150 \\
Auxiliary Engine maintenance & 0.0150 \\
Auxiliary Boilers maintenance & 0.0060 \\
Compression Chiller maintenance & 0.0050 \\
Absorption Chiller maintenance & 0.0025 \\
\hline
\end{tabular}

Table 4 - Emissions factor for MDO [8]

\begin{tabular}{lc}
\hline $\begin{array}{c}\text { Emission } \\
\text { substance }\end{array}$ & $\begin{array}{c}\text { E.F. } \\
{[\mathbf{k g} / \mathbf{k g} \text { fuel] }}\end{array}$ \\
\hline $\mathrm{CO}$ & 0.00277 \\
$\mathrm{CO}_{2}$ & 3.20600 \\
$\mathrm{NO}_{x}$ & 0.08725 \\
$\mathrm{SO}_{x}$ & 0.00264 \\
$\mathrm{PMs}$ & 0.00102 \\
$\mathrm{NMVOC}$ & 0.00308 \\
\hline
\end{tabular}




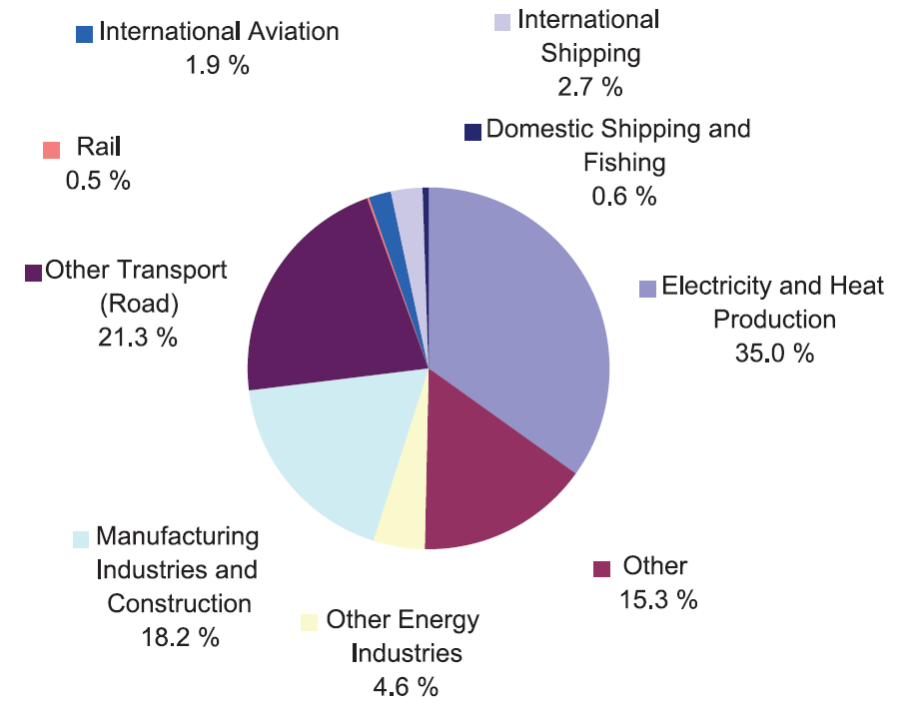

Figure 1: $\mathrm{CO}_{2}$ emissions from fuel combustion in 2014, for different sectors [6]

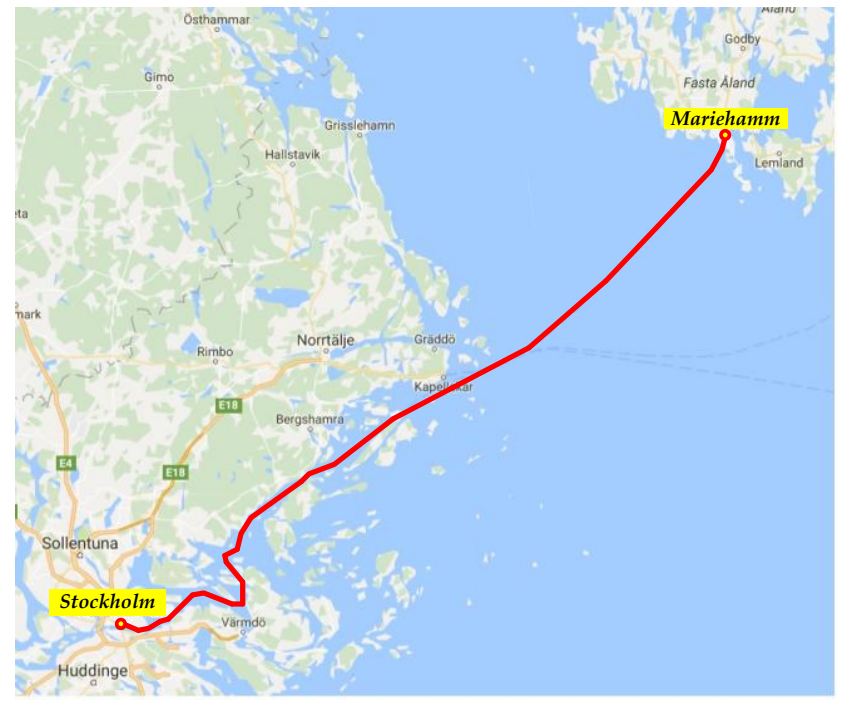

Figure 2 - Schematic of the cruise ship route

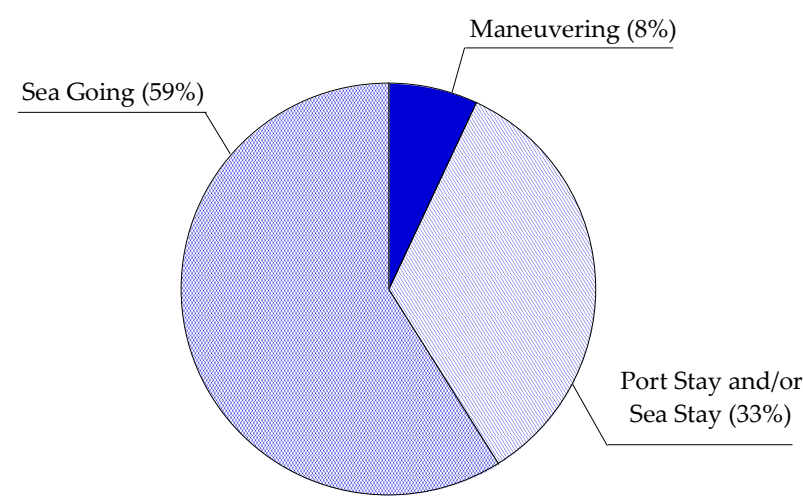

Figure 3 - Operational profile 


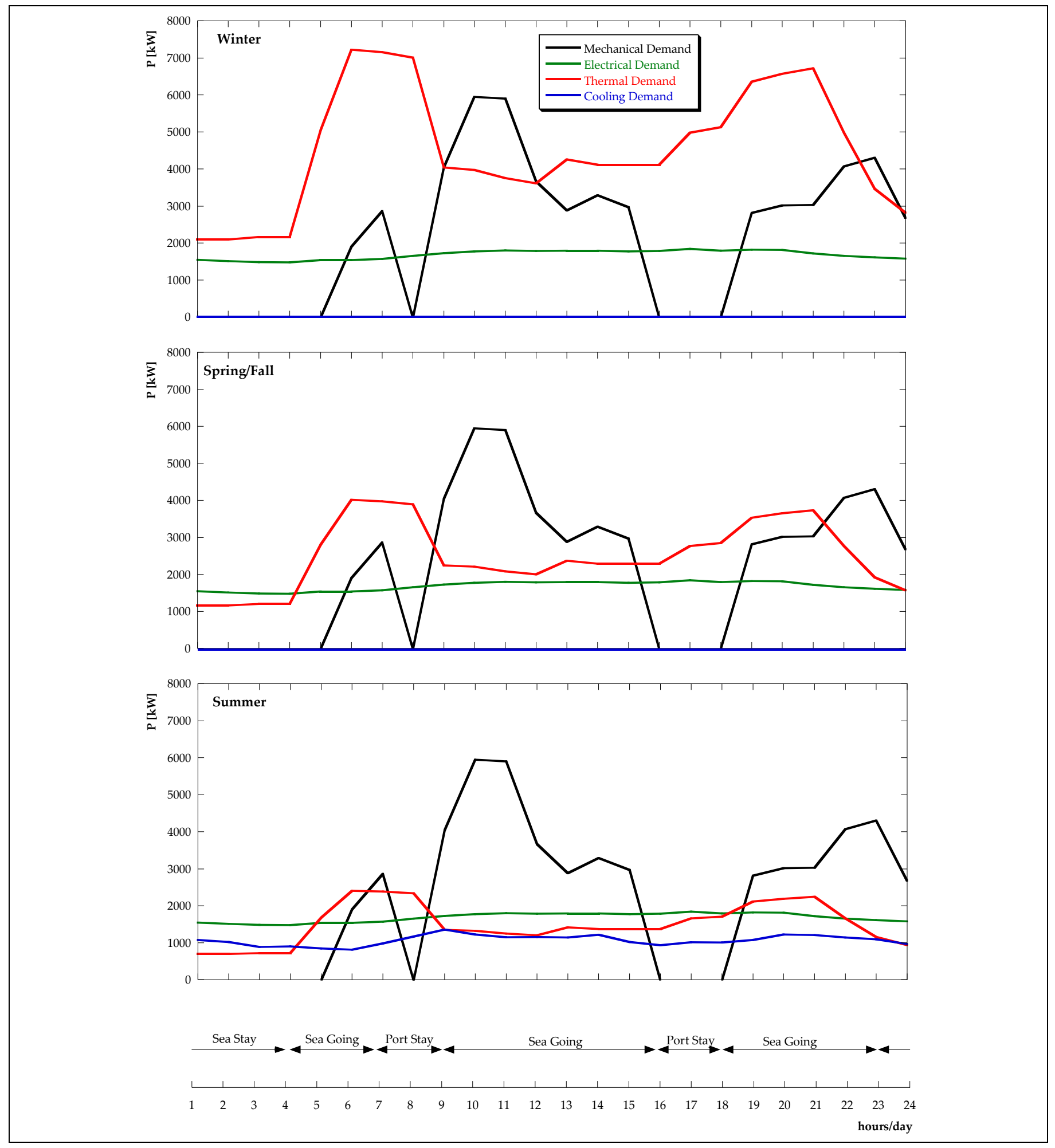

Figure 4 - Hourly load curves for typical days during winter, spring/fall and summer

2 


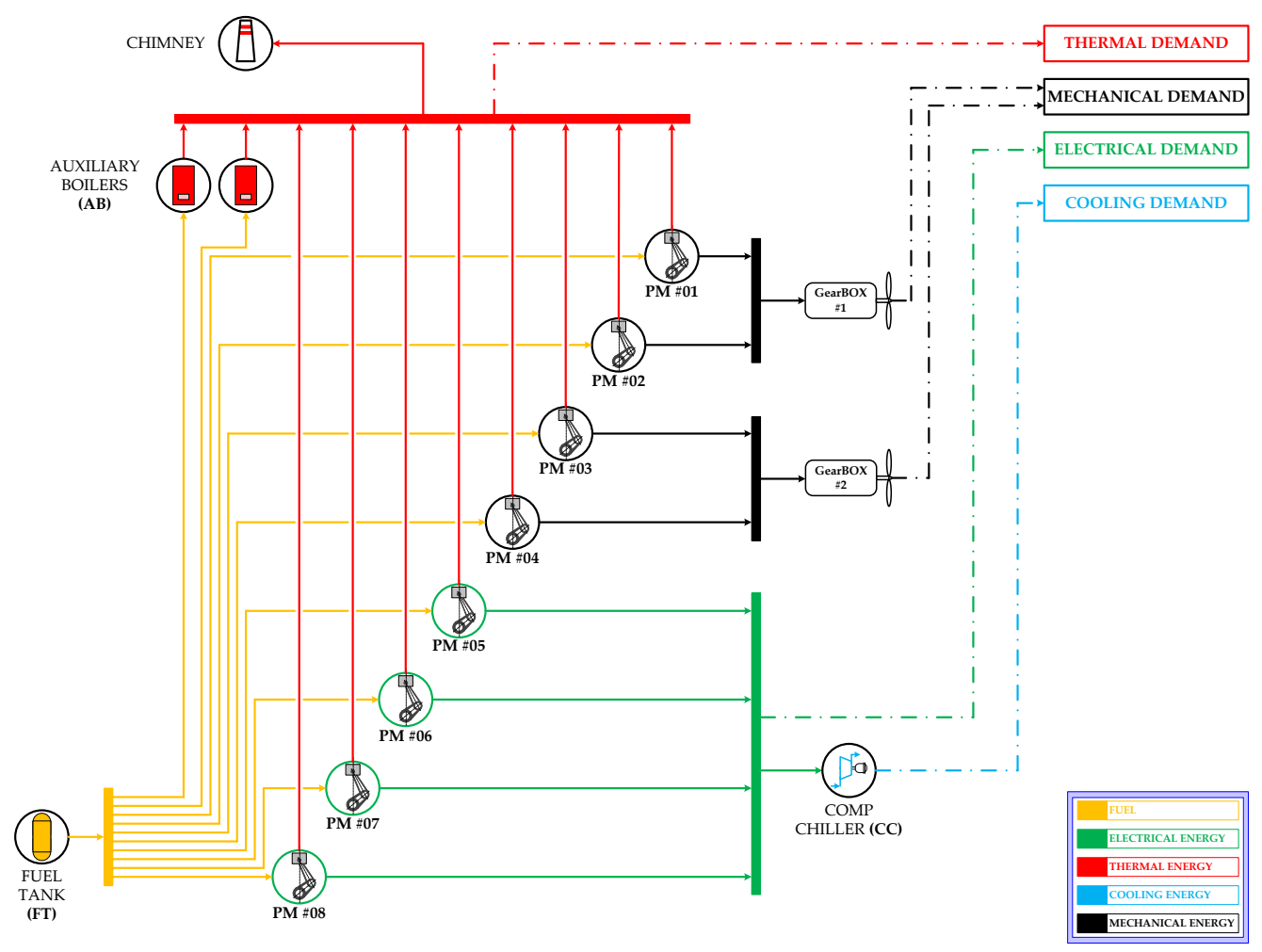

Figure 5 - Base case (BC) layout

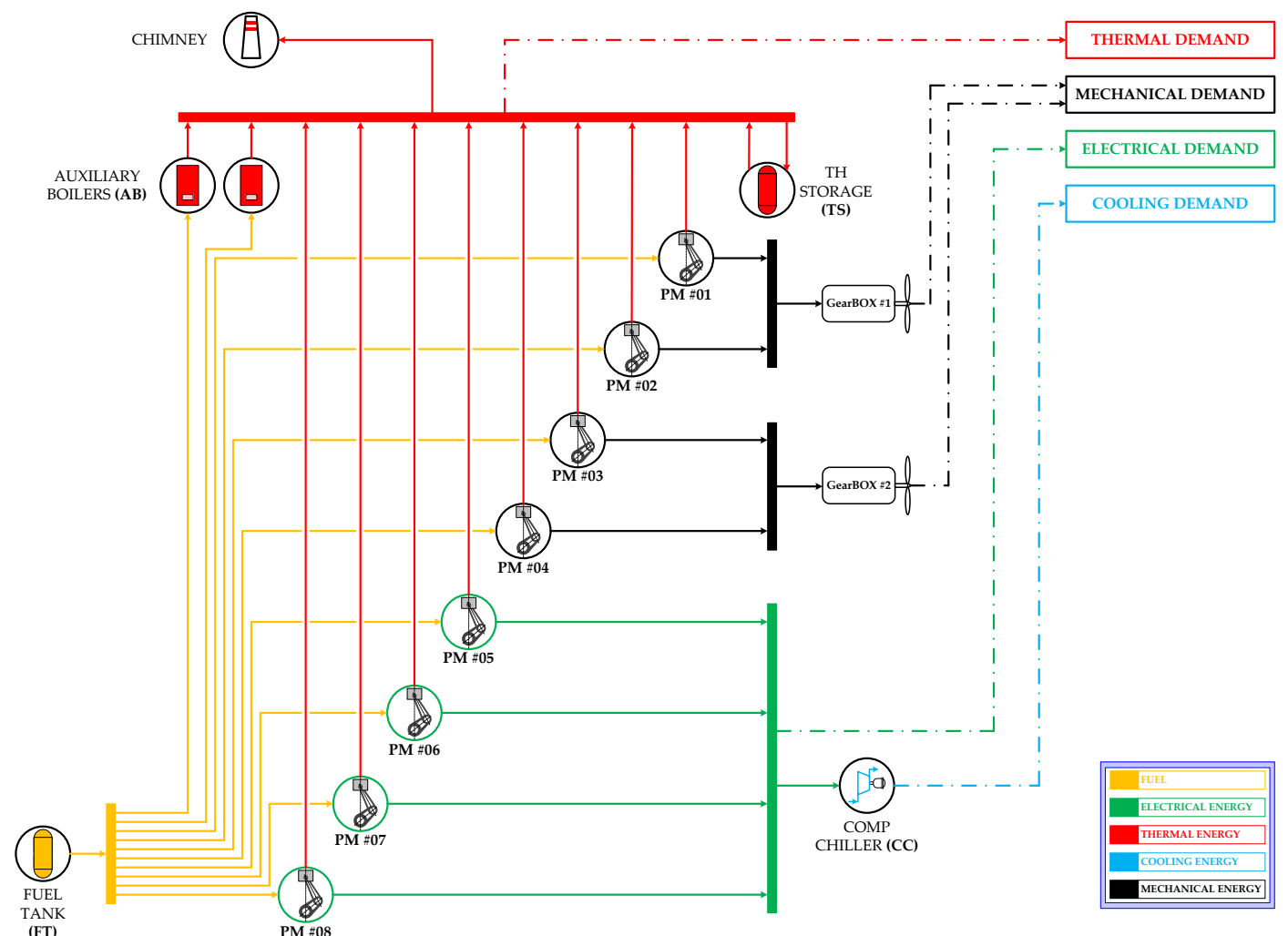

Figure 6 - Optimized load with storage (OL-S) layout 


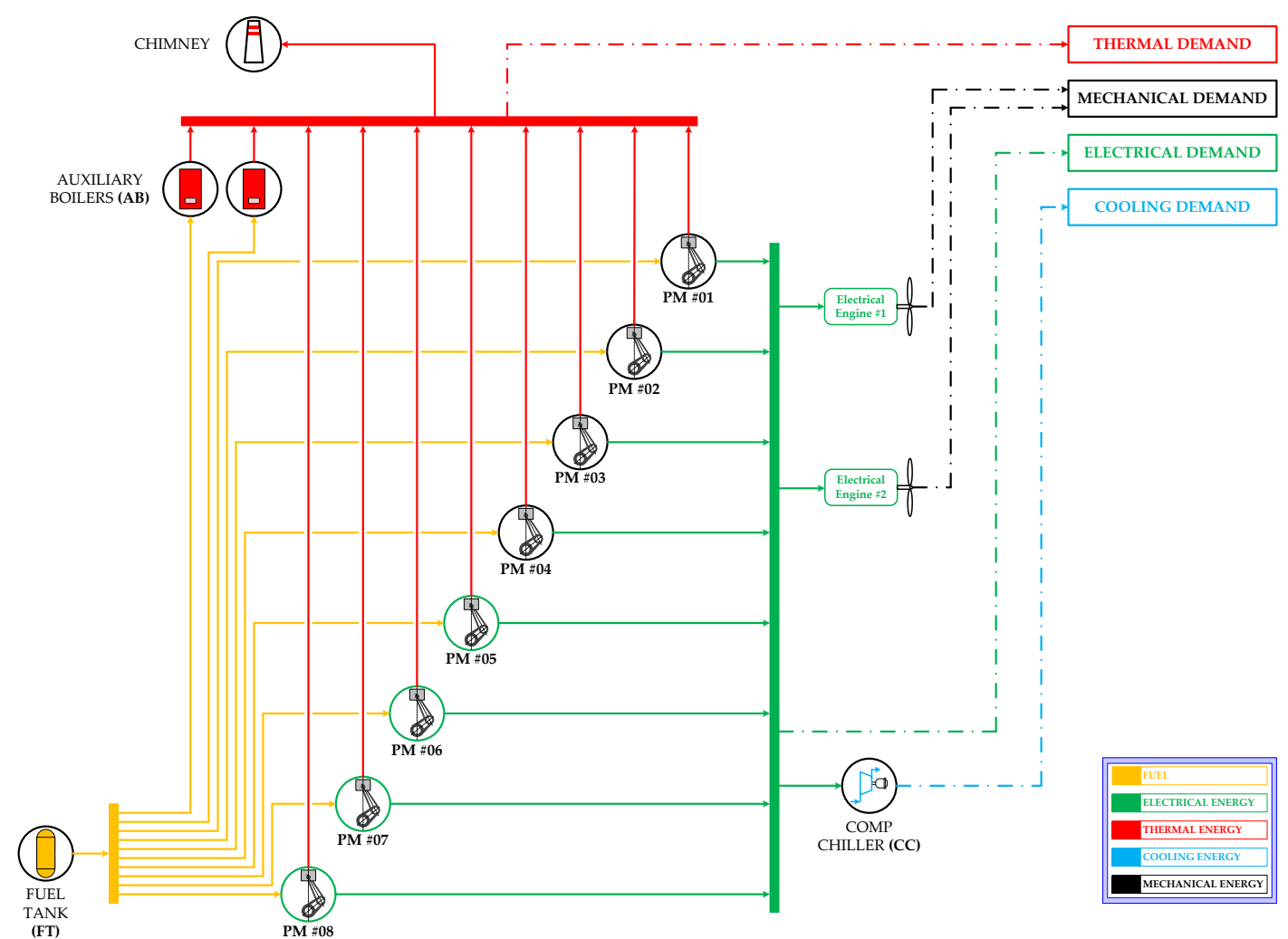

Figure 7 - Hybrid (HY) layout

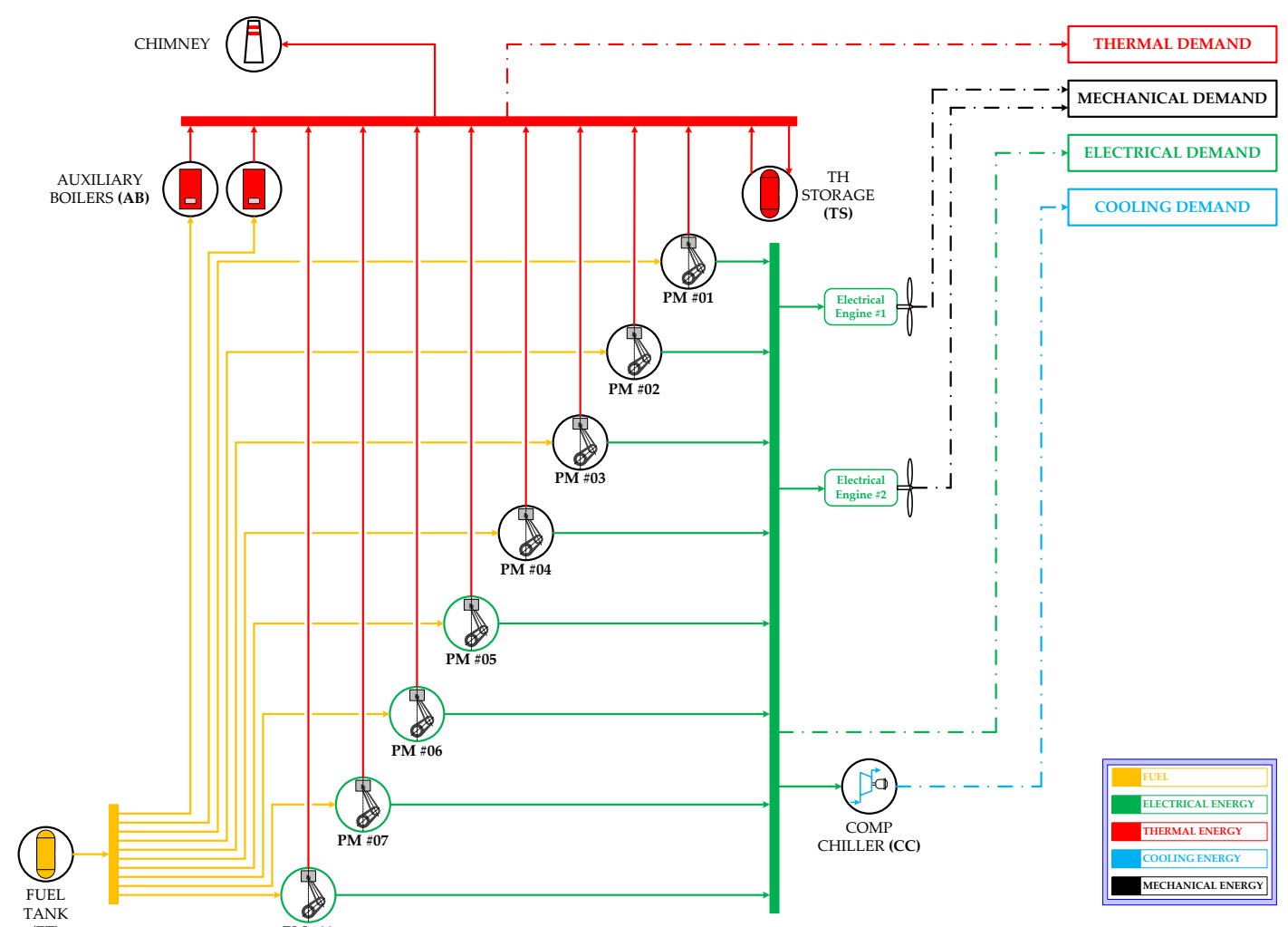

Figure 8 - Hybrid with storage (HY-S) layout 


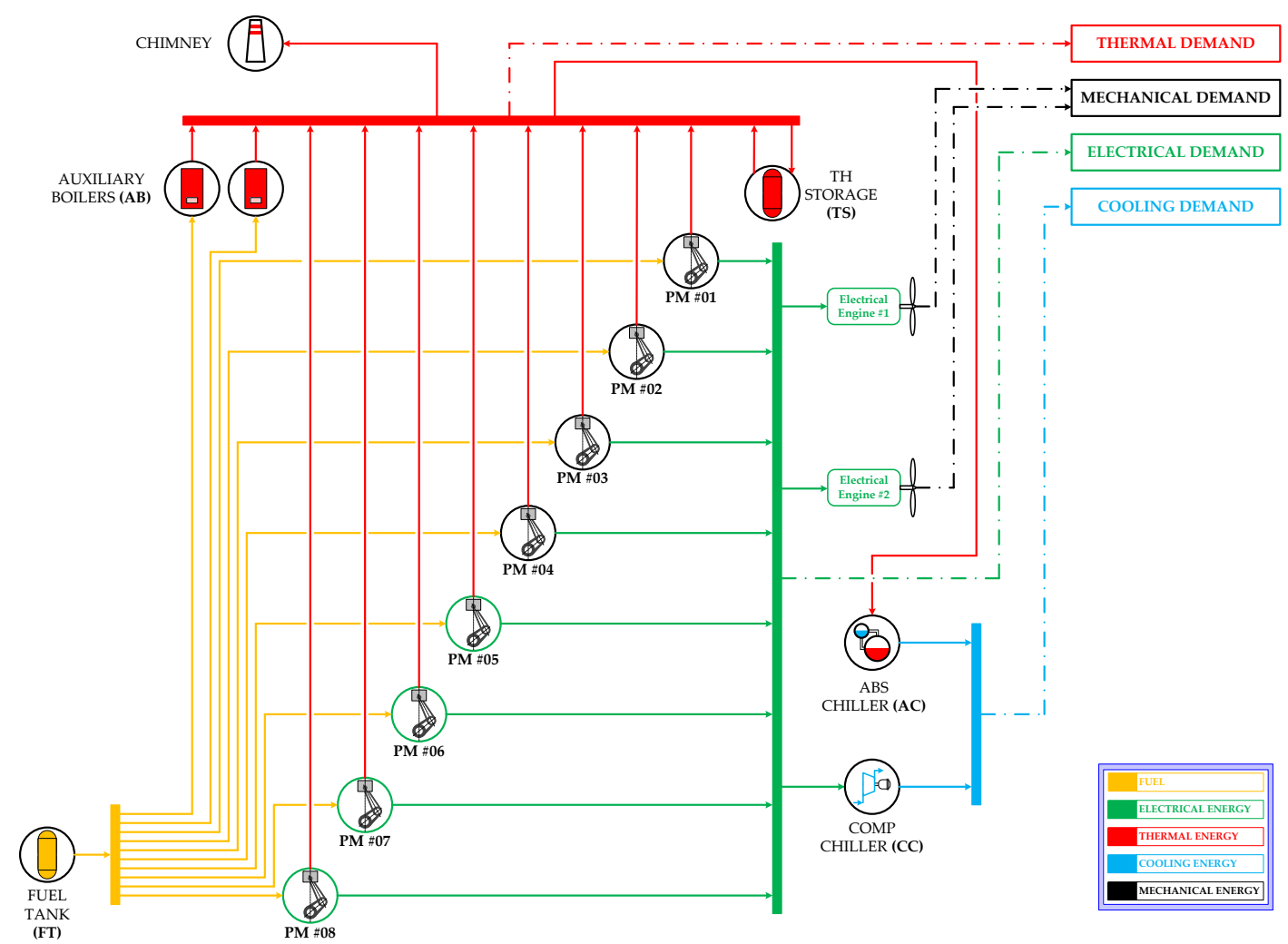

Figure 9 - Hybrid with storage and absorber chiller (HY-S-AC) layout

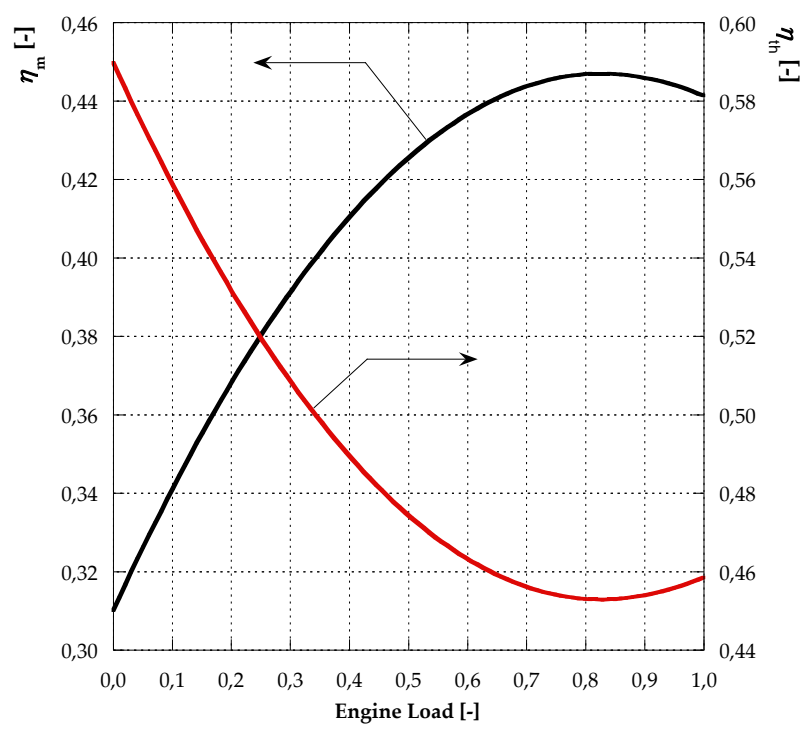

Figure 10 - Mechanical and thermal efficiency as function of load for main engines

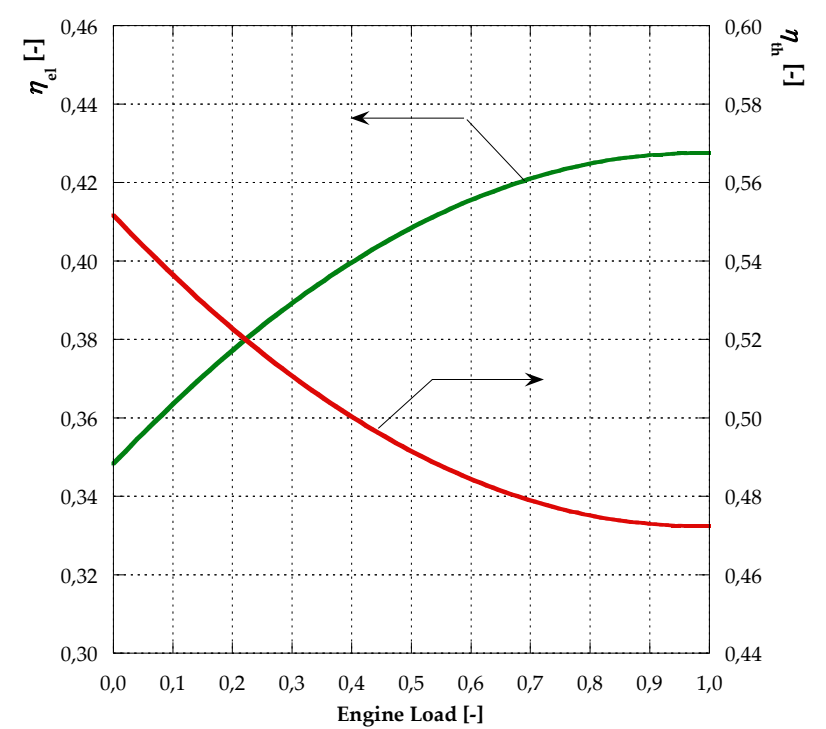

Figure 11 - Electrical and thermal efficiency as function of load for auxiliary engines 


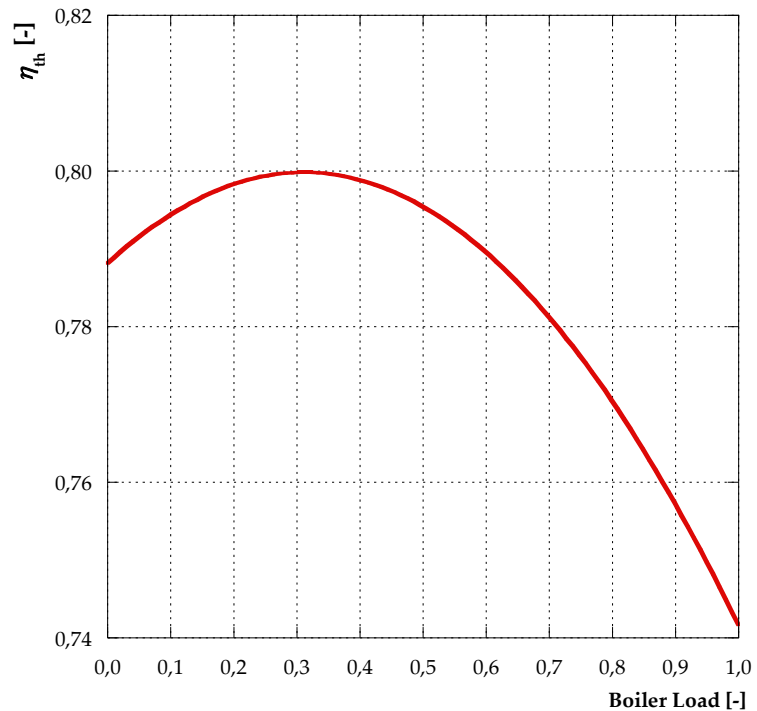

Figure 12 - Thermal efficiency as function of load for auxiliary boilers

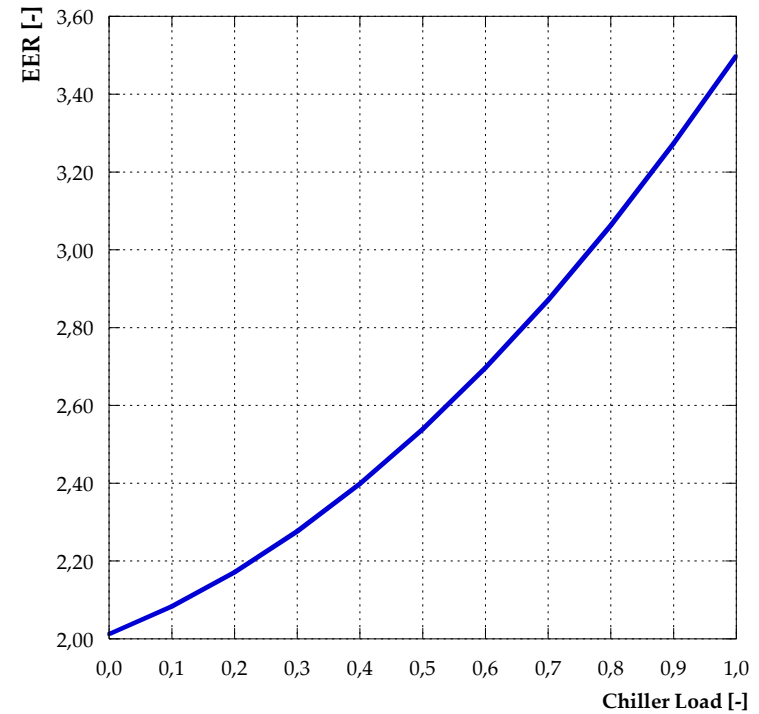

Figure 13 - EER as function of load for compression chiller

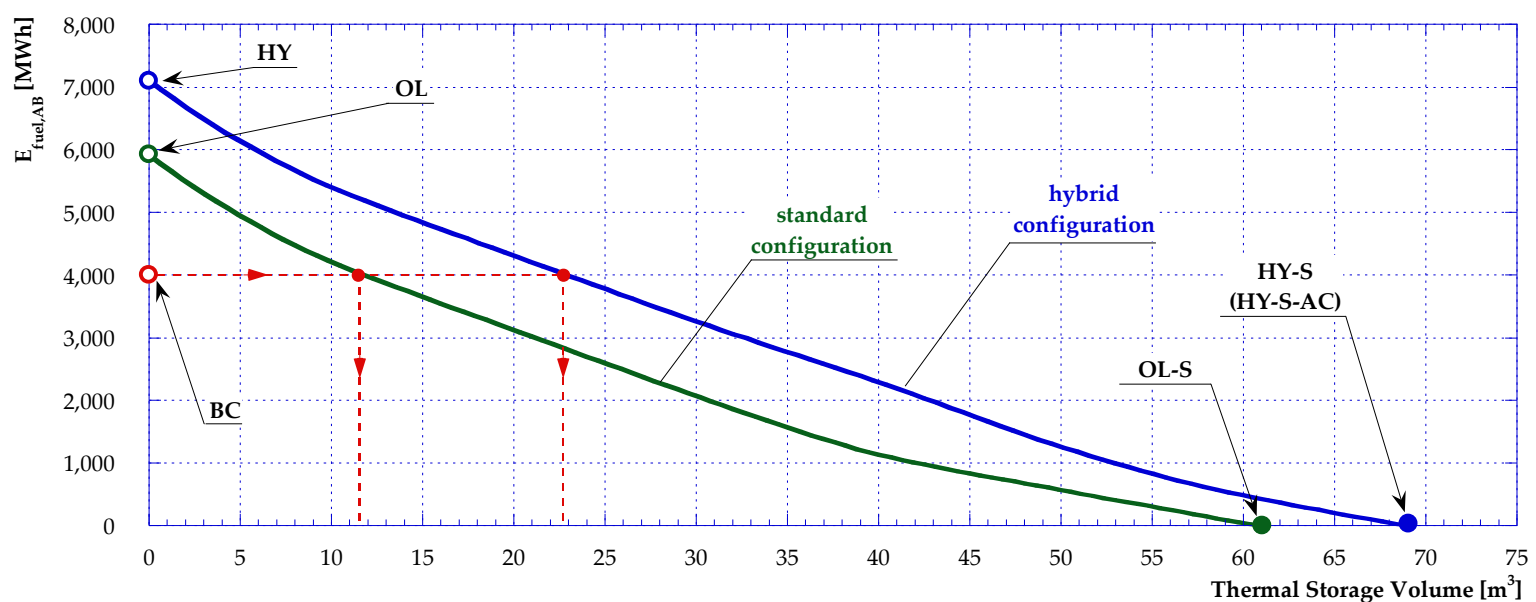

Figure 14 - Annual auxiliary boilers fuel consumption as function of the storage volume

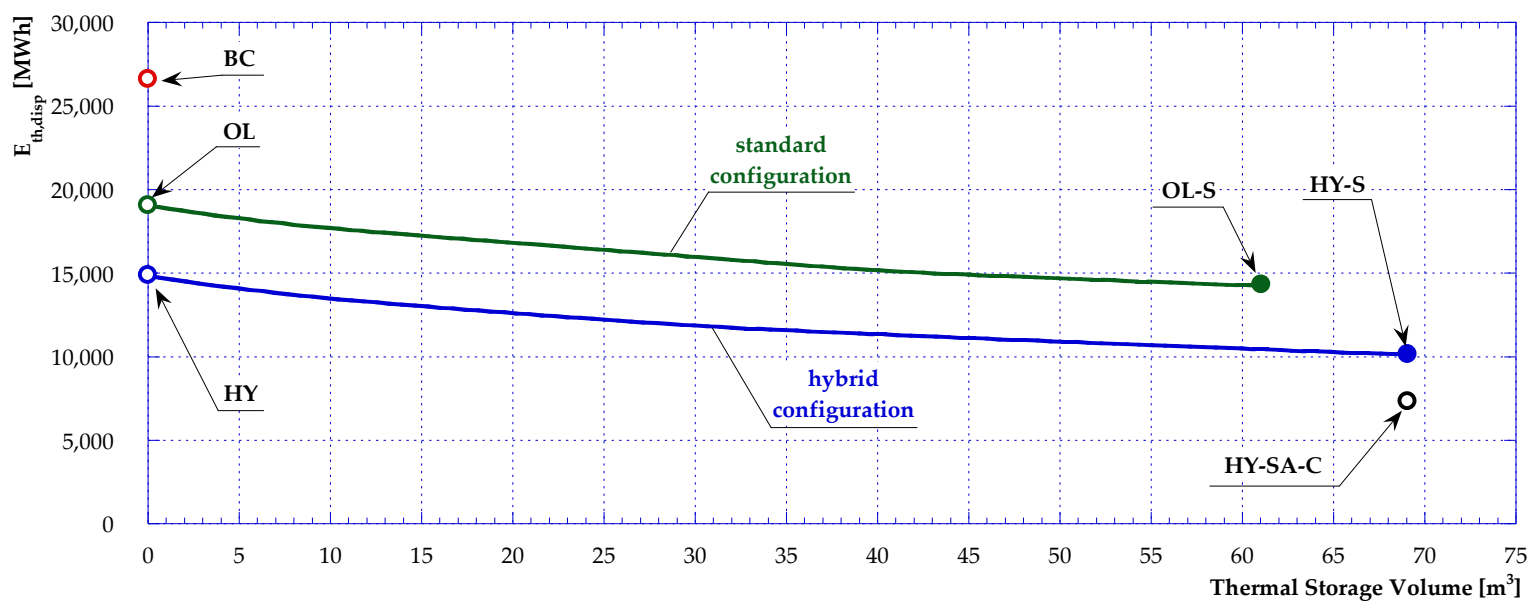

Figure 15 - Annual thermal dissipations as function of the storage volume 


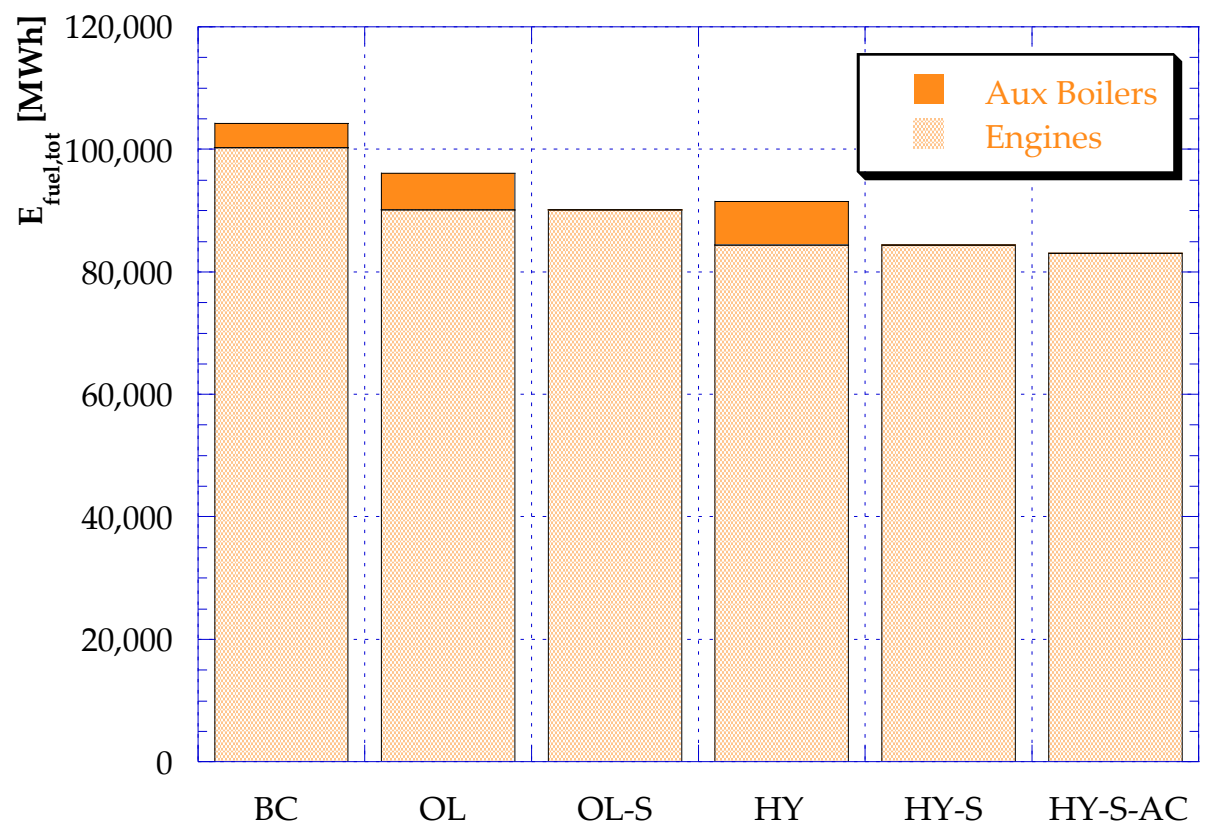

Figure 16-Annual total fuel consumption

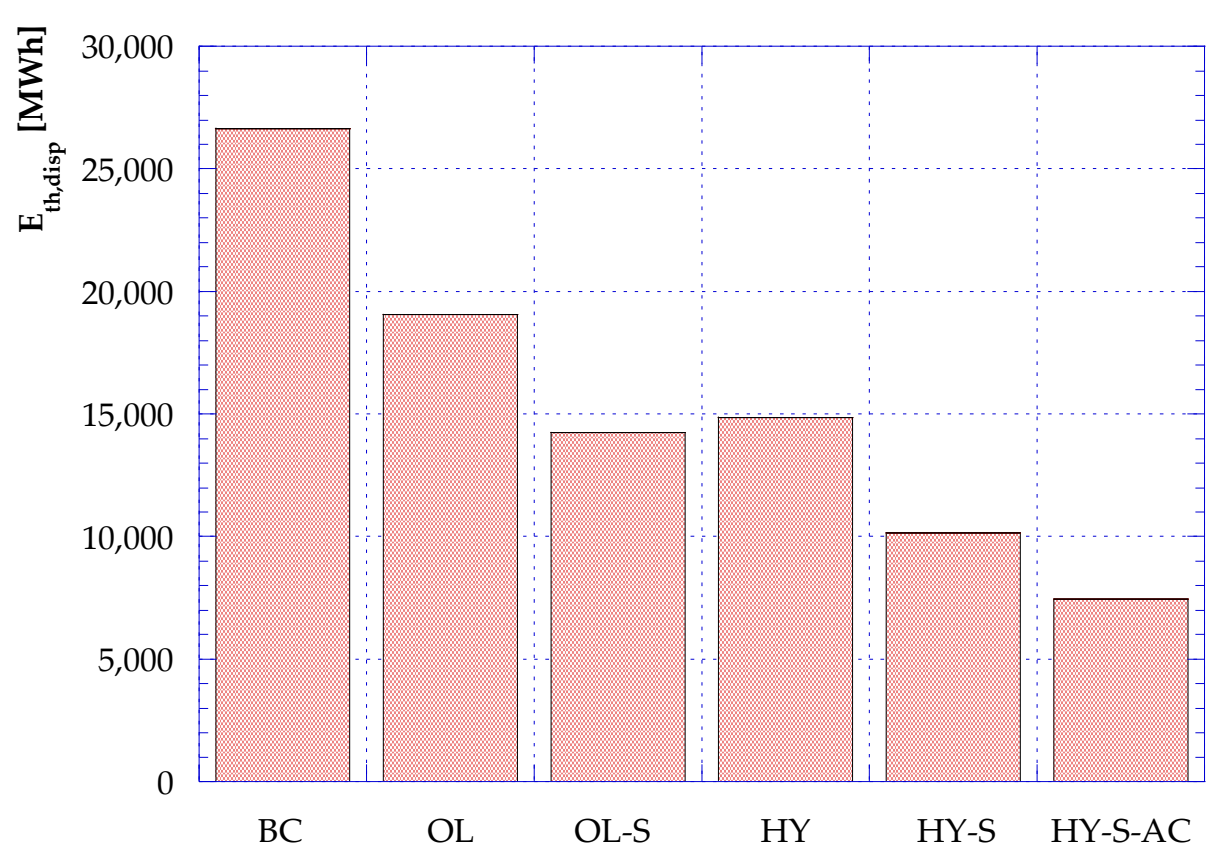

Figure 17 - Annual total dissipations 


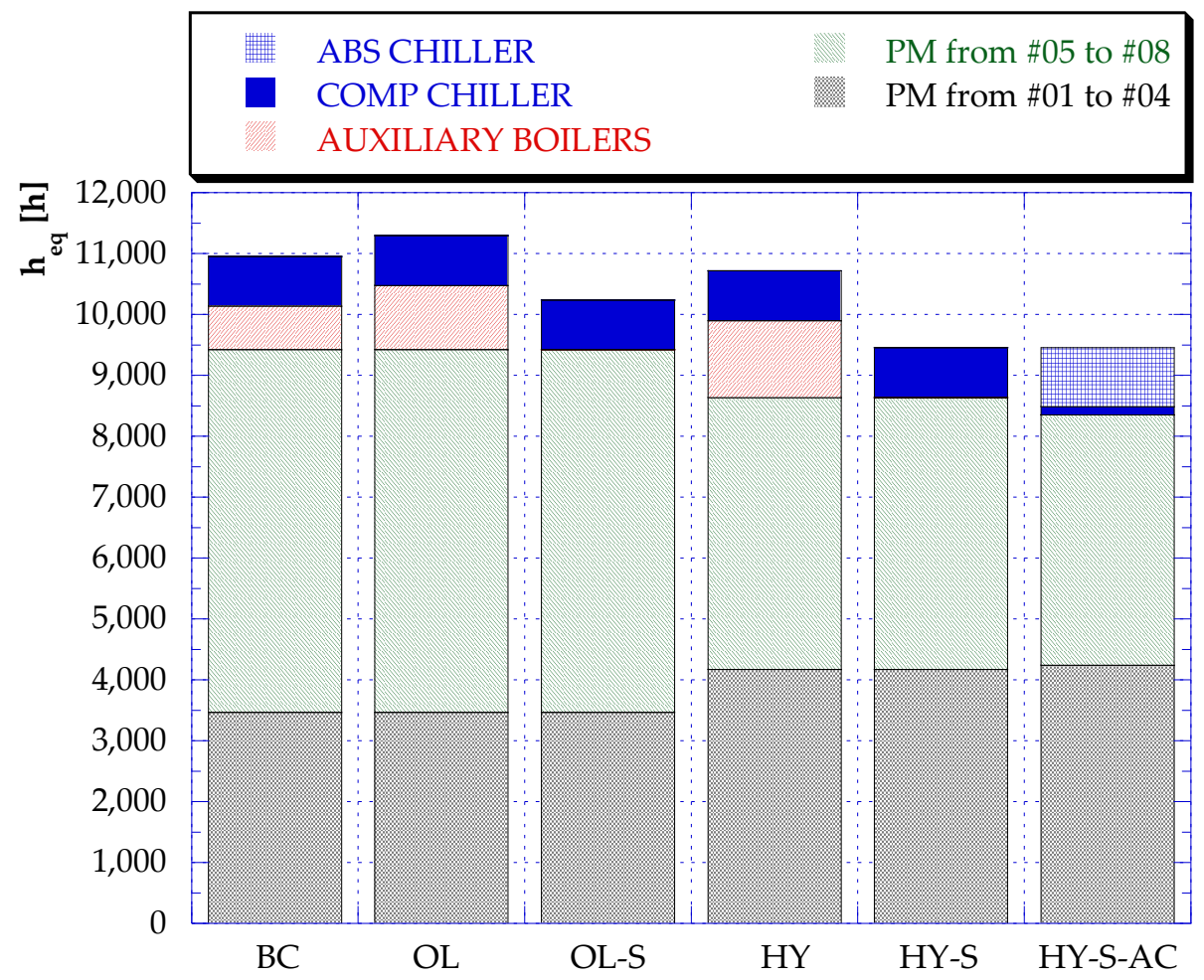

Figure 18 - Annual equivalent hours of operation



Figure 19 - Annual fuel costs and maintenance costs 


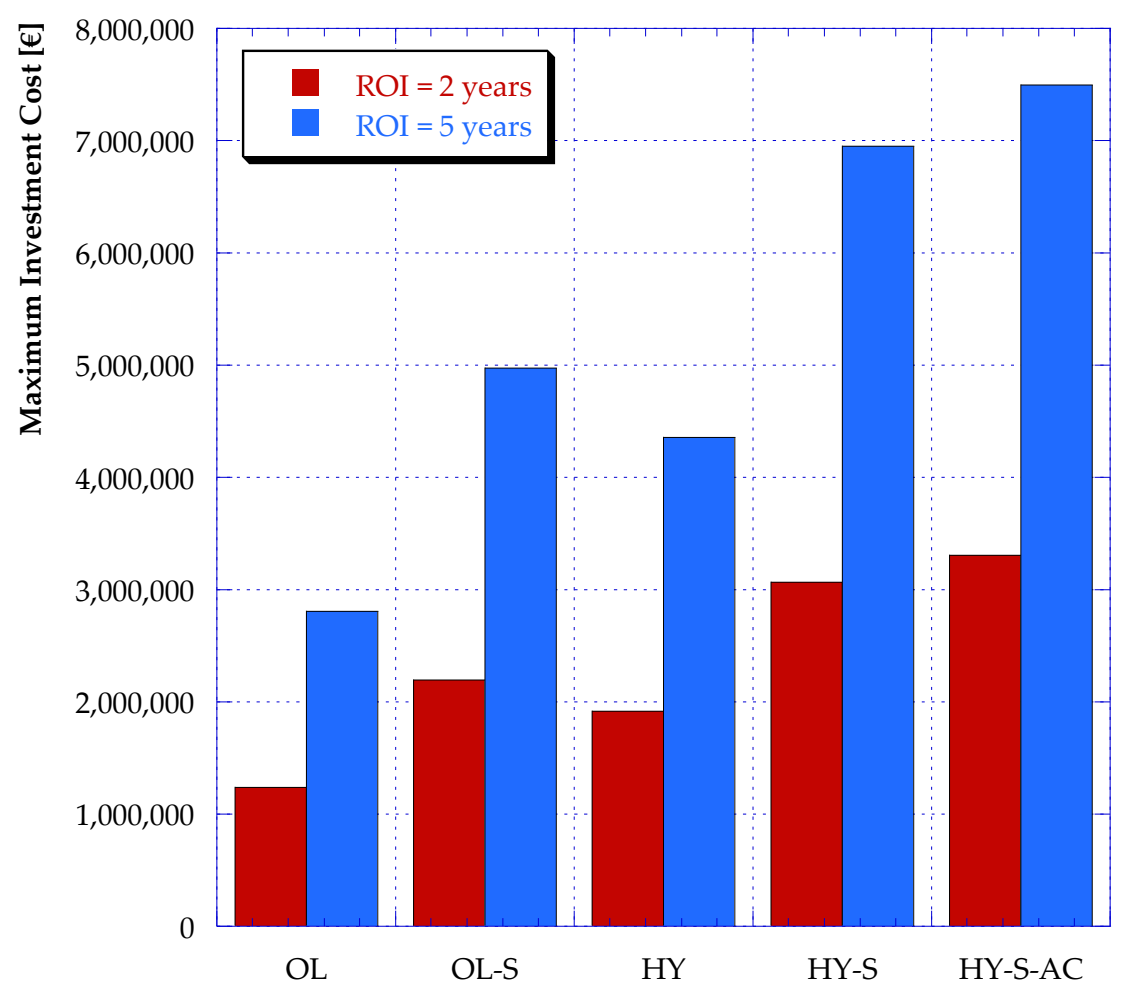

Figure 20 - Maximum investment costs

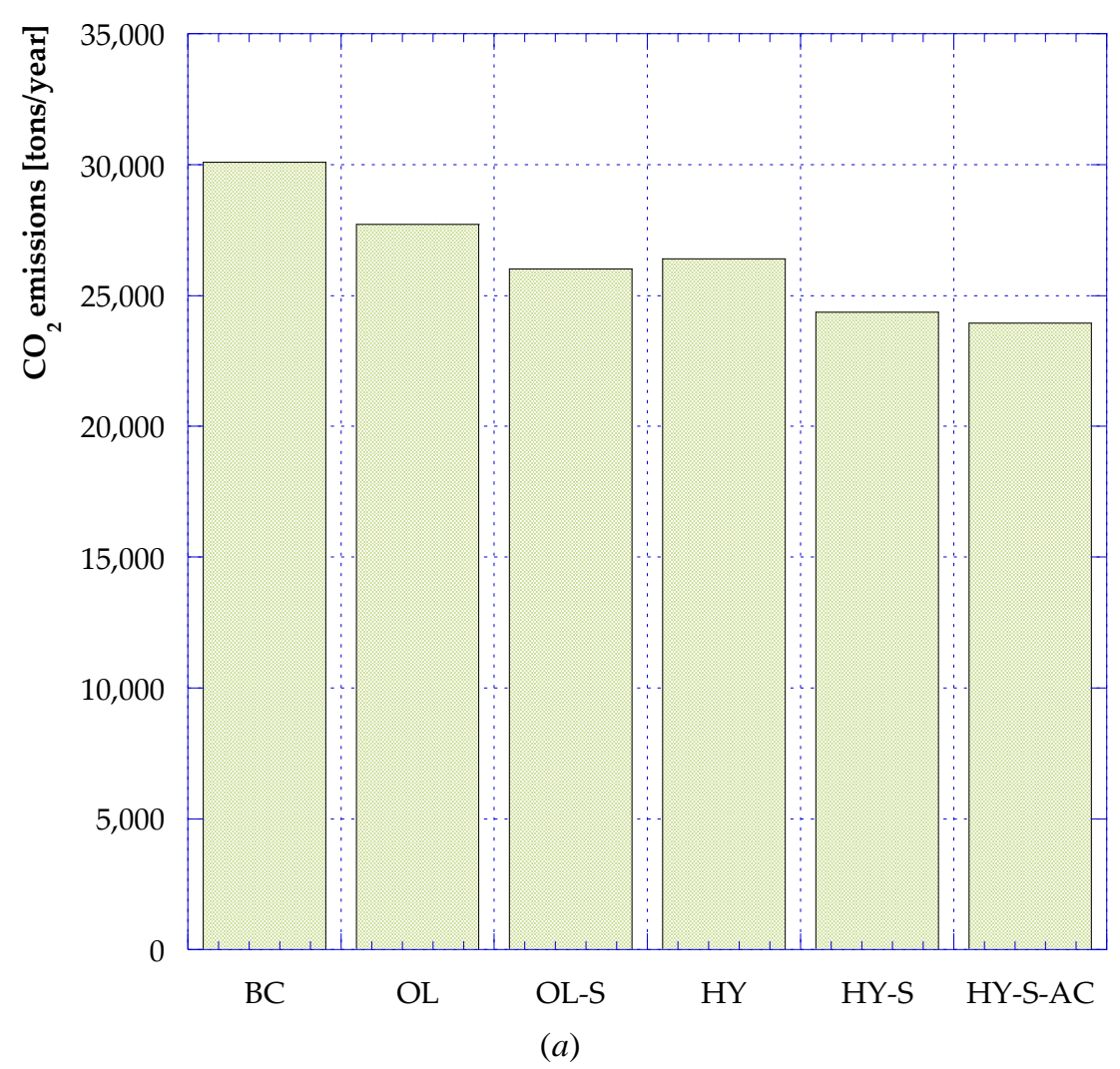




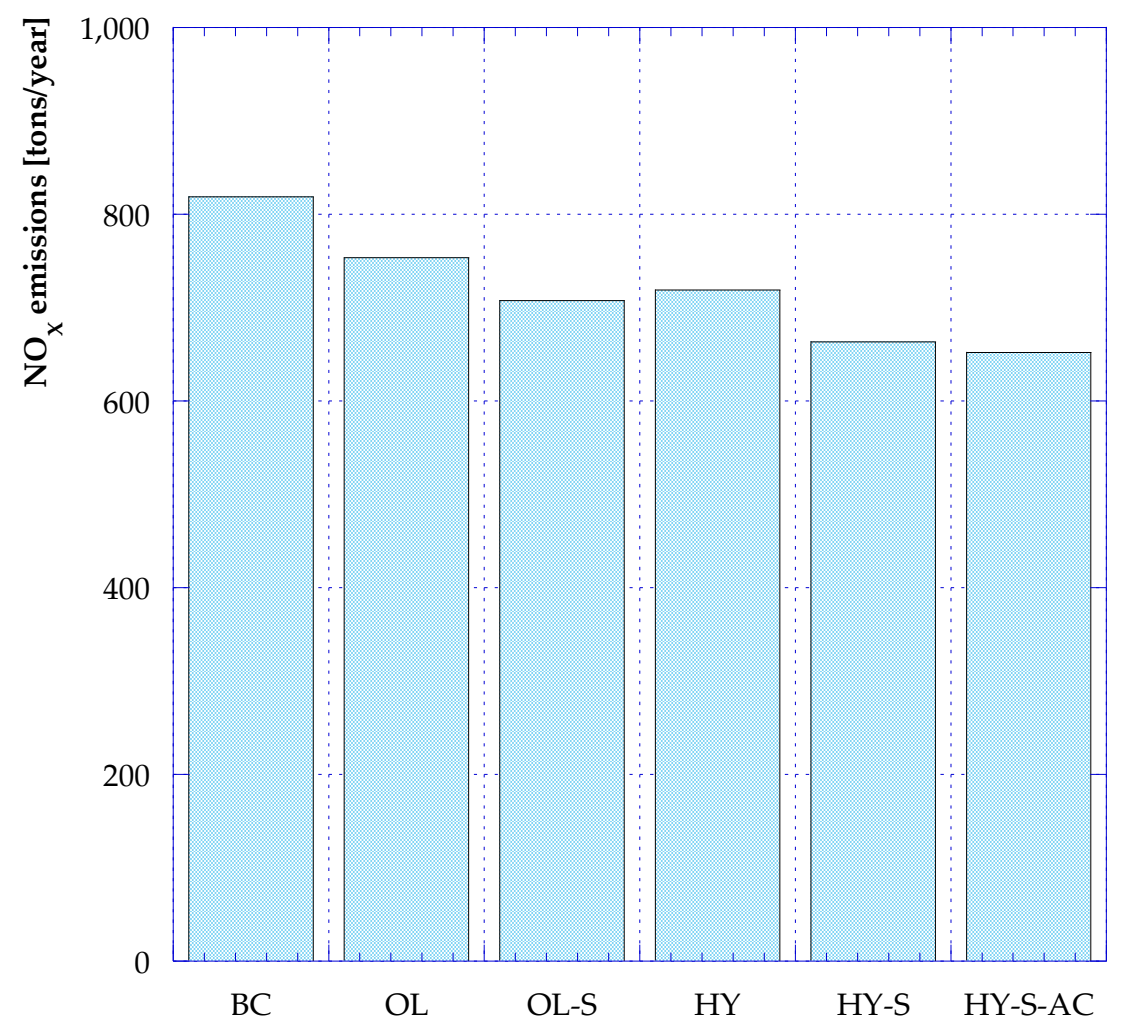

(b)

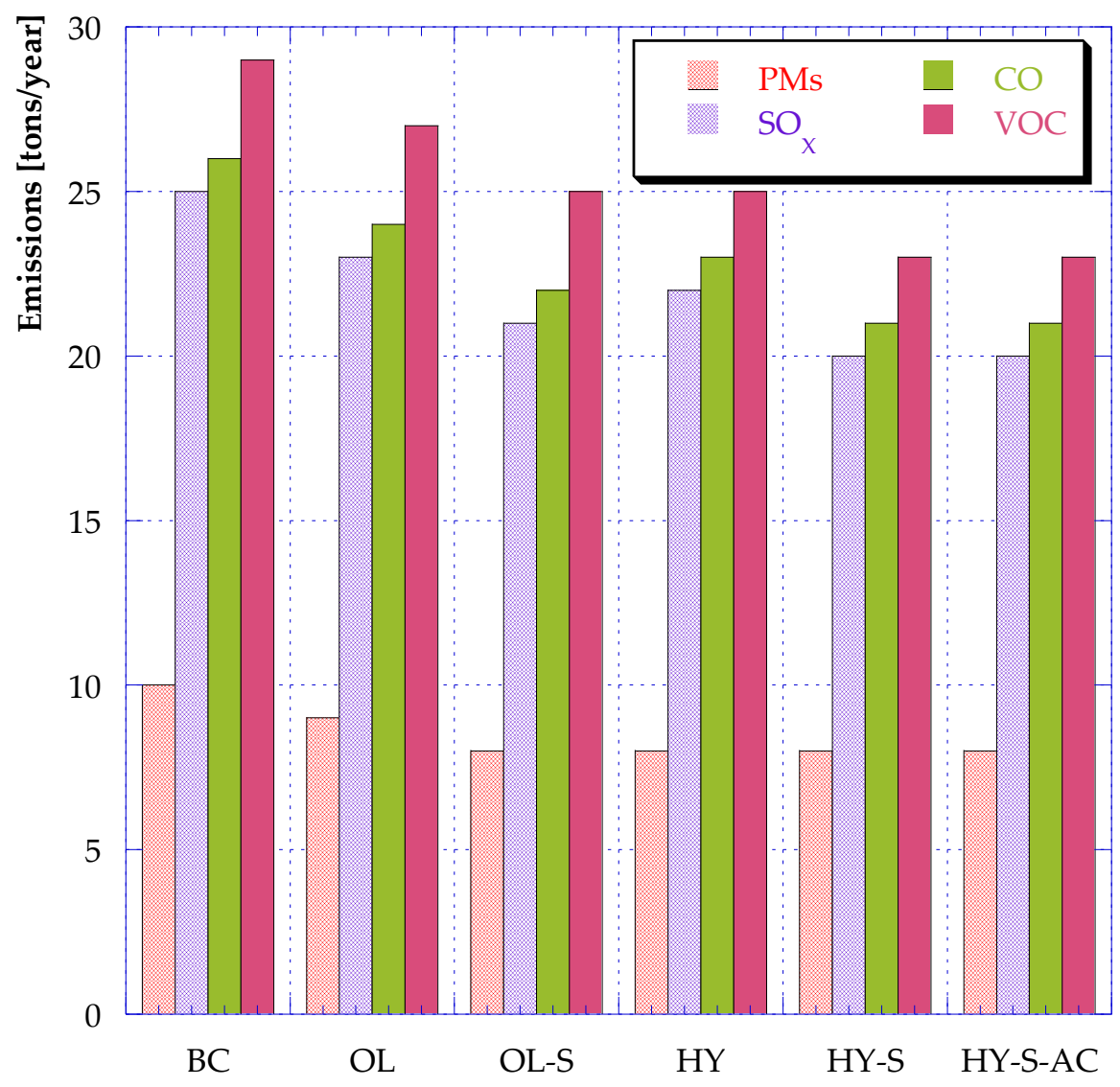

(c)

Figure 21 - Main pollutant emissions: (a) $\mathrm{CO}_{2},(b) \mathrm{NO}_{\mathrm{X}}$ and (c) $\mathrm{CO}, \mathrm{PMs}, \mathrm{SO}_{\mathrm{X}}$, and VOC 